\title{
Monitoring COVID-19 Vaccine Acceptance in Kuwait During the Pandemic: Results from a National Serial Study
}

This article was published in the following Dove Press journal: Risk Management and Healthcare Policy

\author{
Eiman AIAwadhi' \\ Dina Zein (D) ${ }^{2}$ \\ Fatmah Mallallah (iD ${ }^{3}$ \\ Nour Bin Haider' \\ Anower Hossain (iD ${ }^{4}$ \\ 'Faculty of Public Health, Department of \\ Epidemiology and Biostatistics, Kuwait \\ University, Kuwait City, Kuwait; ${ }^{2}$ Faculty \\ of Public Health, Department of Health \\ Policy and Management, Kuwait \\ University, Kuwait City, Kuwait; ${ }^{3}$ Ministry \\ of Health, Hanoi, Kuwait; ${ }^{4}$ Institute of \\ Statistical Research and Training, \\ University of Dhaka, Dhaka, Bangladesh
}

Correspondence: Eiman AIAwadhi Faculty of Public Health, Kuwait University, PO Box 24923, Safat, I3 I I0, Kuwait

Tel +965 246-34380

Email eiman.alawadhi@ku.edu.kw
Background: With COVD-19 cases on the rise globally and two approved vaccines, determining vaccine acceptance is imperative to avoid low inoculation rates. The aim of this study was to evaluate the changes and determinants of vaccine acceptance among citizens and non-citizens, over time during the pandemic in Kuwait.

Methods: Data were obtained from the COVID-19 Snapshot Monitoring (COSMO Kuwait) study that was implemented according to the WHO tool for behavioral insights on COVID19. Data was collected online, every two weeks throughout the pandemic. Individuals living in Kuwait during the pandemic were surveyed, representing an independent sample of the population during each data collection wave.

Results: A total of 7241 adults living in Kuwait participated. Sixty-seven percent of those participating agreed to take a vaccine if it was available and recommended. However, the proportion of vaccine acceptance drastically dropped overtime as COVID-19 related restrictions were eased, among citizens ( 73 to $47 \%$ ) and noncitizens ( 80 to $60 \%$ ). Some factors associated with increased odds of agreeing to take the COVID-19 vaccine, among citizens and non-citizens, included increased frequency of informing oneself about the virus (OR, 1.34-1.83; 95\% confidence interval 1.16-2.55), having high versus low confidence in doctors (OR, 1.79-2.11; CI 1.17-3.80), increased agreement with containment policies (OR, 1.111.27; CI 1.05-1.41), expressing more fears and worries (OR, 1.05-1.12; 1.01-1.24), and the increased perceived likelihood of getting infected with influenza (OR, 1.3-1.4; CI 1.031.84). Decreased odds of agreement were associated with increased age (OR, 0.37-0.61; CI 0.26-0.95), being female (OR, 0.56-0.62; CI 0.43-0.73), and not taking the influenza vaccine in 2019 (OR, 0.61; CI 0.43-0.87).

Conclusion: Vaccine acceptance was multifactorial, heterogenous among citizens and noncitizens, and changed over time. While acceptance was relatively high, it decreased throughout the pandemic and as restrictions in the country loosened. This increase in vaccine hesitancy reveals a challenge in achieving high inoculation levels, and the need for effective vaccine-promotion campaigns and increased health education in the country.

Keywords: vaccine acceptance, coronavirus, Kuwait, COVID-19 vaccine

\section{Introduction}

As COVID-19 global cases continue to rise, pharmaceutical companies globally are competing to develop a vaccine rapidly. According to the World Health Organization (WHO), there are currently over 50 COVID-19 vaccine candidates in development, two of which have been approved for full use as of Dec, 18, 2020. ${ }^{1,2}$ However, while high-income countries such as Kuwait are securing 
agreements to obtain enough COVID-19 vaccines, ${ }^{3,4}$ this unprecedented and rapid development of the vaccines can raise safety concerns among people that can be a barrier to full population inoculation against COVID-19. Producing an effective vaccine may only be the beginning of a long, challenging race to gain widespread acceptance of the vaccine. $^{5}$

Past pandemics such as Influenza A (H1N1) and SARS highlighted vaccine hesitancy in certain populations. ${ }^{6}$ Studies during and after these pandemics indicated that people are often concerned about the side effects of vaccines and their effectiveness. ${ }^{7}$ Certain groups, such as those with lower-income or no formal educational background, have shown to be more hesitant due to misconceptions, or fears of vaccines. ${ }^{8,9}$

Public acceptance of vaccines varies globally, and in 2019 the WHO declared vaccine hesitancy a top ten threat. ${ }^{10}$ Between 2015 and 2019, Figueiredo et al mapped global trends in public confidence in vaccines across 149 countries. They identified that confidence in vaccines remains low in Europe when compared to other continents and countries such as India, Mexico, and Thailand. Between 2015 and 2019 vaccine confidence had increased in the aforementioned countries. Within Europe, France in 2015 had had the lowest estimated percentage of respondents agreeing that vaccines are safe (8.9\%, 95\% HPD interval $7 \cdot 2-10 \cdot 5)$. Vaccine acceptance was highest in Argentina, Liberia and Bangladesh and lowest in Japan. In some countries such as Indonesia, confidence in vaccines dropped between 2015 and 2019. Across three elements, Indonesia saw a $13.8 \%$ drop in vaccine safety, $14 \%$ decrease in importance, and $12.2 \%$ decrease in effectiveness. This decline was influenced by religious leaders questioning the safety of the measles, mumps, and rubella vaccine. ${ }^{11}$ In 2020, a global survey on the potential acceptance of a COVID-19 vaccine was conducted in 19 countries. ${ }^{12}$ Unfortunately, neither Kuwait nor close neighboring countries were included in this study. However, findings indicated that $71.5 \%$ of participants would be somewhat likely to take a COVID-19 vaccine, and $61.4 \%$ would accept their employer's recommendation to take the vaccine.

Therefore, amid the global pandemic, it is crucial to determine vaccine acceptance in Kuwait as a vaccine may be available in the country by the end of $2020 .{ }^{13,14}$ While the Kuwaiti government is keen on providing its people with a vaccine, the public's potential acceptance of taking the COVID-19 vaccine has not yet been assessed. Changes in people's acceptance level where the epidemiology of COVID-19 and its related policies have erratically varied in the country have not yet been evaluated either. Furthermore, evaluating vaccine acceptance among citizens and non-citizens living in Kuwait is crucial to determine disparities and avoid low inoculation rates; especially if inoculation is not mandated. Understanding the level of people's vaccine acceptance and its determinates is essential as it can aid policymakers. Health officials can tailor and deliver practical and strategic vaccine-acceptance messages to minimize hesitancy and misinformation regarding the vaccine. This study aims to assess vaccine acceptance, among citizens and non-citizens, overtime during the pandemic in Kuwait. The study will also evaluate the determinants of COVID-19 vaccine acceptance among citizens and non-citizens.

\section{Methods}

\section{Study Design and Participants}

Our study used data from the "Kuwait COVID-19 Snapshot Monitoring (COSMO Kuwait)" study. ${ }^{15}$ COSMO Kuwait is a serial cross-sectional study that aims to monitor knowledge, risk perceptions, preventive behaviors, and public trust during the COVID-19 outbreak in Kuwait. All countries participating in the COSMO studies follow the WHO standard protocol, ${ }^{16}$ which ensures similar objectives, data collection method, survey tool, and data presentation and analyses methods among the eleven participating countries.

Data was collected using a 15-minute online survey, where a convenience sampling technique was utilized. The survey was administered using several social media platforms: WhatsApp, Instagram, Twitter, Snapchat, as well as emails. Data collection started at the most critical time in the country, during the complete lockdown, and continued every two weeks for 2-4 days during each wave. The political and epidemiological situation represented by each data collection wave is highlighted in Figure 1.

The study participants consisted of citizens and noncitizens aged 18-74 years, who were living in Kuwait during the COVID-19 pandemic. Participants were only able to complete the survey once, and an IP-based duplicate protection system was used to ensure validity. A brief introduction to the study and its objective were provided to the participants. Following the introduction, participants were requested to provide consent in order to begin 


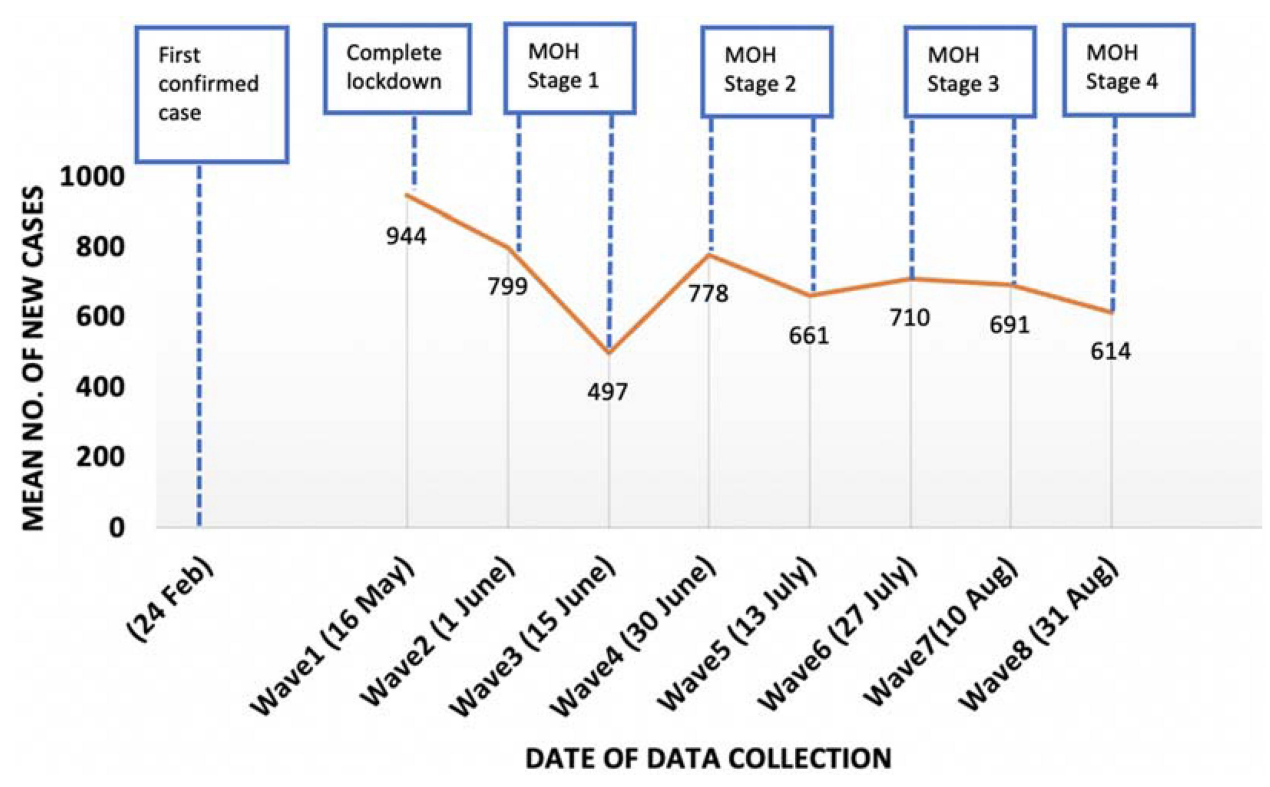

Figure I National epidemic trend of new COVID-19 cases and political situation in Kuwait, May-August 2020.

Notes: Complete lockdown, closure of the entire country's facilities and institutions, with exception to supermarkets, and full curfew with a maximum of 2 hours per day for exercise; Ministry of Health (MOH) stage I of the government's restoration to normality plan, with partial curfew from 6:00 p.m. to 6:00 a.m., and some reopening of industrial activities, public services, and home delivery for restaurants and retail shops; MOH Stage 2, with partial curfew from 8:00 p.m. to 6:00 a.m., and further openings including workplaces (less than 30\%), finance and banking, commercial complexes, retail shops, restaurants (take away only), gardens and public parks; MOH Stage 3, with partial curfew from 9:00 p.m. to 05:00 a.m., and opening of workplaces (less than 50\%), social welfare home visits, hotels, resorts, and hotel apartments, taxis, mosques to allow group Friday prayers; MOH Stage 4, with no curfew, and opening of workplace (more than 50\%), restaurants and cafes (with social distancing), public transportations, personal care shops (salons, shaving, spa), and public and private sports courts.

completing the survey. This was done similarly to the original WHO questionnaire.

\section{Data Measurement Tool}

The survey tool used by the COSMO studies was developed by the University of Erfurt Germany and the COSMO group. ${ }^{16}$ The survey included previously validated questions; however, it was further modified through 3 rounds of validation. ${ }^{16}$ The English questionnaire was translated and back-translated to Arabic, in order to be administered in both languages.

The data used in this study were obtained from the following sections of COSMO Kuwait's survey: sociodemographic, knowledge about COVID-19, risk perceptions, preparedness and perceived self-efficacy, preventive measures, information and trust, policies, panic and fears, and influenza. The primary outcome of this study was based on a policy question that assessed vaccine acceptance among participants: If a vaccine becomes available and is recommended for me, I would get it. It was measured using a 7-point Likert scale from 1 (strongly disagree) to 7 (strongly agree). Values from 1-4 indicated disagreement or less likely to agree (Disagree), while 5-7 indicated agreement or more likely to take the vaccine (Agree).
Predictors included sociodemographic characteristics (Table 1), knowledge about COVID-19, risk perceptions, preparedness and perceived self-efficacy, preventive measures, information and trust, policies, panic and fear, and influenza (Table 2). All numeric predictors were all measured using a Likert scale from 1-7. To assess real knowledge, responses to the five questions on treatment, transmission, transmission route, incubation and immunity for each participant were summed and then scaled to 1-7 (Cronbach $\alpha$ 0.6). Participants' knowledge relating to preventative measures was assessed using 14 questions (Cronbach $\alpha$ 0.7). Correct preventative measures included washing hands, avoiding touching eyes, nose and mouth, using sanitizers, staying home when sick, covering mouth when coughing, wearing a face mask and social distancing. Misinformation regarding preventative measures included taking herbal supplements, food supplements, avoiding meat, getting flu shot, using antibiotics, drinking giber tea, and using homoeopathic remedies). A score of 1 was assigned if the participant responded to preventative measure with a "yes", and 0 if otherwise. Taking preventative measures was assessed by calculating how many of the 14 preventative measures the participant took (Cronbach $\alpha$ 0.8), of which only the seven correct 


\begin{tabular}{|c|c|c|c|c|c|c|c|}
\hline \multicolumn{2}{|l|}{$\frac{\mathscr{0}}{\frac{\partial}{\pi j}}$} & & $\begin{array}{l}\frac{*}{3} \\
\frac{1}{8} \\
\dot{0} \\
\text { v }\end{array}$ & 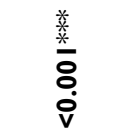 & 䔡 舌 & 岂 & 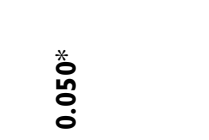 \\
\hline \multirow{4}{*}{ 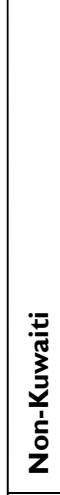 } & 选 & $\begin{array}{l}\hat{a} \\
\stackrel{N}{N}\end{array}$ & 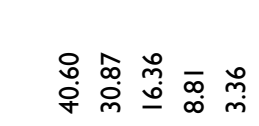 & $\begin{array}{l}\text { 足 } \\
\text { 广 } \\
\text { 呙 }\end{array}$ & 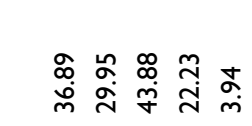 & 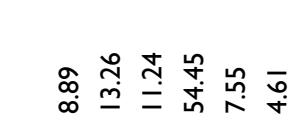 & 유ㅇㅝㅛ \\
\hline & 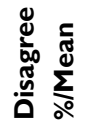 & ஸू. & 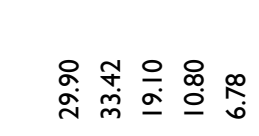 & $\underset{m}{\bar{j}}$ & 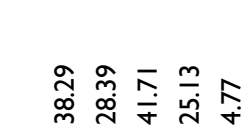 & 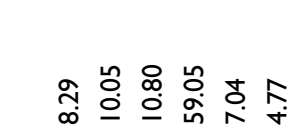 & 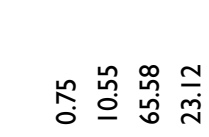 \\
\hline & ๙ே & 옴 & 总 & 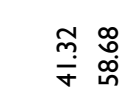 & 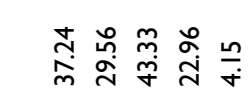 & 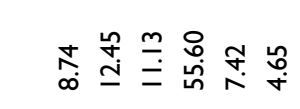 & 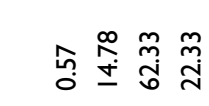 \\
\hline & s & ํํำ & 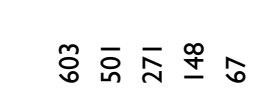 & 䒘 & 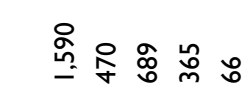 & $\stackrel{\leftrightarrow}{\underline{m}} \stackrel{\infty}{=} \underset{\infty}{ \pm} \stackrel{\infty}{=}$ & 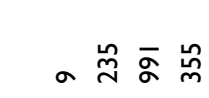 \\
\hline \multicolumn{2}{|l|}{ 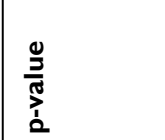 } & & $\begin{array}{l}\frac{*}{*} \\
\frac{*}{*} \\
\dot{0} \\
\dot{v}\end{array}$ & $\begin{array}{l}\frac{*}{*} \\
\frac{*}{0} \\
\dot{0}\end{array}$ & 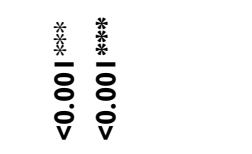 & 䊝 & 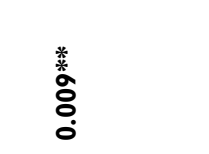 \\
\hline \multirow{4}{*}{ 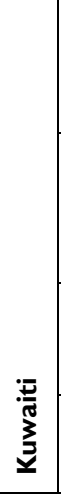 } & 这 & స్ & 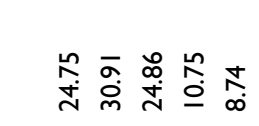 & 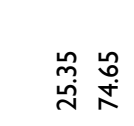 & 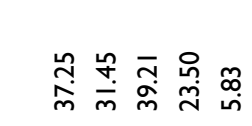 & 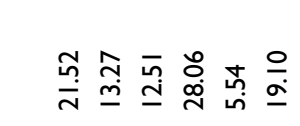 & 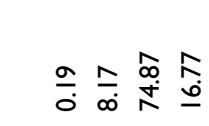 \\
\hline & 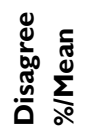 & 命 & 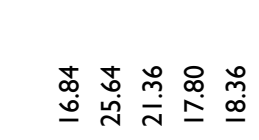 & $\begin{array}{l}\stackrel{\infty}{0} \\
\stackrel{0}{\sigma} \\
\stackrel{\infty}{\infty}\end{array}$ & 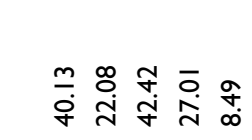 & 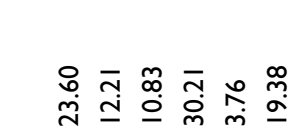 & 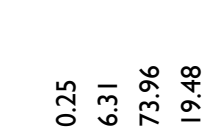 \\
\hline & হ̄ & ¿ & 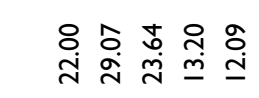 & 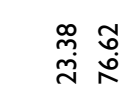 & 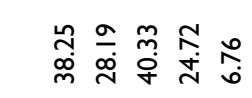 & 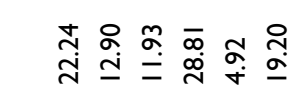 & 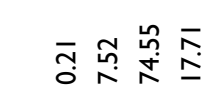 \\
\hline & $=$ & 芌 & 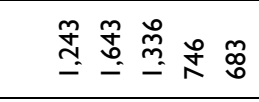 & 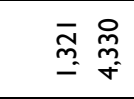 & 至 & 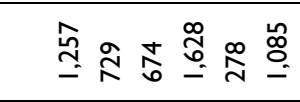 & $\simeq \stackrel{\sim}{\sim} \frac{m}{\sim} \bar{q}$ \\
\hline \multicolumn{2}{|l|}{ 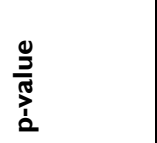 } & & $\begin{array}{l}\frac{}{*} \\
\frac{*}{*} \\
\\
\dot{0} \\
\mathbf{v}\end{array}$ & 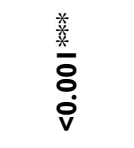 & 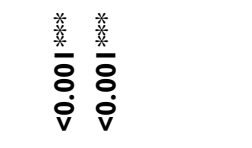 & $\begin{array}{l}\frac{*}{*} \\
\frac{*}{\dot{*}} \\
\dot{\mathrm{v}}\end{array}$ & $\begin{array}{l}\frac{*}{*} \\
\frac{\text { to }}{8} \\
\dot{0}\end{array}$ \\
\hline & 这 & 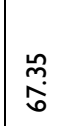 & 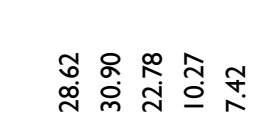 & 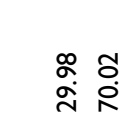 & 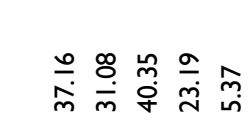 & 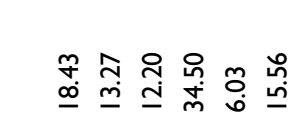 & 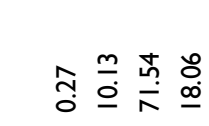 \\
\hline & 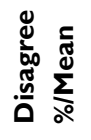 & $\begin{array}{l}\stackrel{L}{0} \\
\stackrel{m}{m}\end{array}$ & 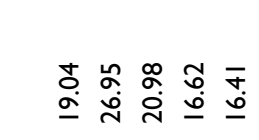 & $\stackrel{\infty}{\bar{N}} \overline{\bar{\infty}}$ & 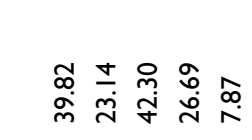 & 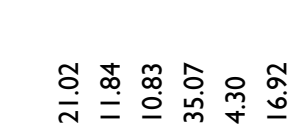 & 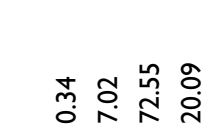 \\
\hline & ১ু & 迎 & 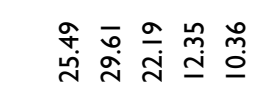 & $\underset{\sim}{\stackrel{\sim}{\sim}} \stackrel{\infty}{i}$ & 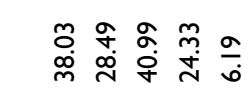 & 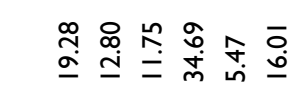 & 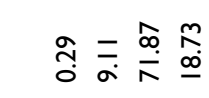 \\
\hline ڤึ & $=$ & $\overline{\mathbb{N}}$ & 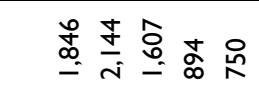 & 隹 & 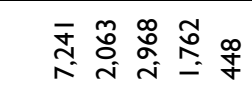 & 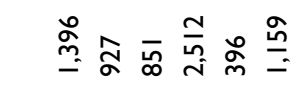 & 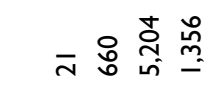 \\
\hline 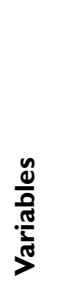 & & ثِّ & 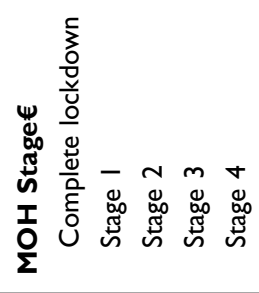 & 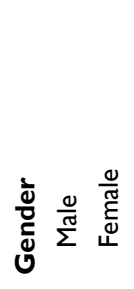 & 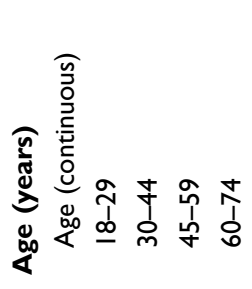 & 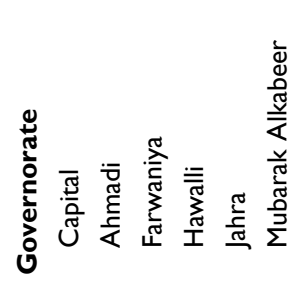 & 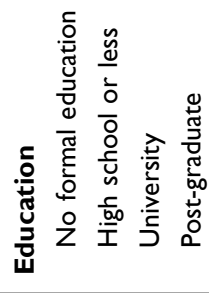 \\
\hline
\end{tabular}




\begin{tabular}{|c|c|c|c|c|c|c|}
\hline ثัँ & Iิ & 菅 & 웅 & $\frac{\alpha}{0}$ & $\overline{\bar{O}}$ & $\begin{array}{l}\text { 萨 } \\
\stackrel{0}{0} \\
0\end{array}$ \\
\hline 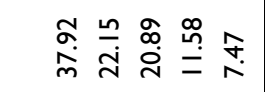 & 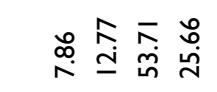 & 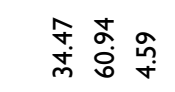 & 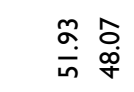 & 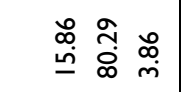 & 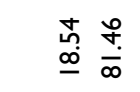 & 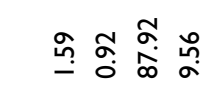 \\
\hline 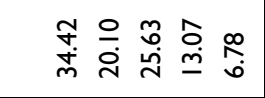 & 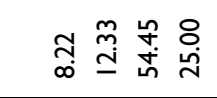 & 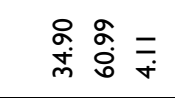 & 宐 & 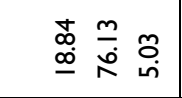 & 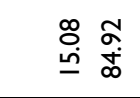 & 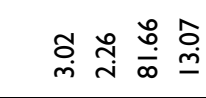 \\
\hline 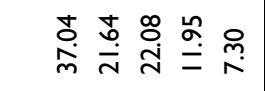 & 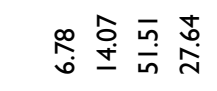 & 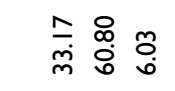 & 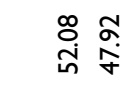 & 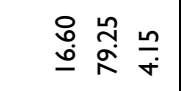 & 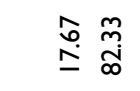 & 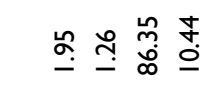 \\
\hline 总 青 & 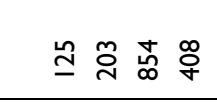 & 竎 。 & $\underset{\infty}{\infty} \stackrel{\widetilde{\Omega}}{\curvearrowright}$ & 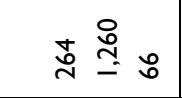 & 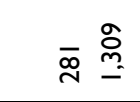 & 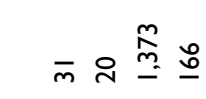 \\
\hline $\begin{array}{l}\frac{*}{*} \\
\frac{0}{8}\end{array}$ & 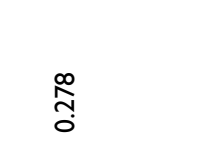 & $\begin{array}{l}\frac{*}{3} \\
\frac{*}{0} \\
\dot{0} \\
\dot{v}\end{array}$ & $\frac{*}{\frac{*}{0}}$ & $\stackrel{8}{\circ}$ & $\begin{array}{l}\stackrel{*}{*} \\
\text { đo } \\
0\end{array}$ & $\stackrel{\tilde{p}_{0}^{n}}{o}$ \\
\hline 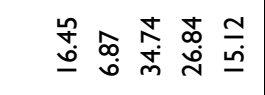 & 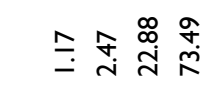 & 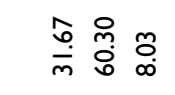 & 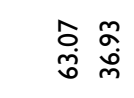 & 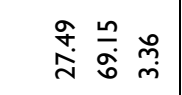 & 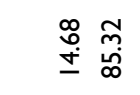 & 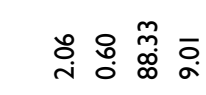 \\
\hline 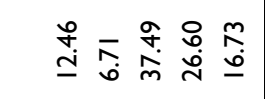 & 울 守 & 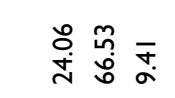 & 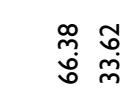 & 莳 $\frac{\infty}{\sigma} \underset{m}{m}$ & 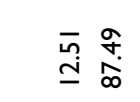 & 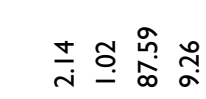 \\
\hline 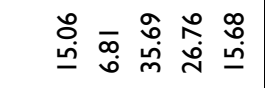 & 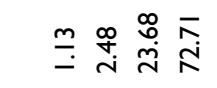 & 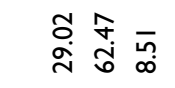 & 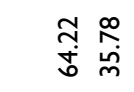 & $\underset{\sim}{\stackrel{\infty}{\sim}} \stackrel{0}{\sigma} \underset{0}{\stackrel{m}{m}}$ & $\begin{array}{l}m \\
\stackrel{m}{0} \\
\stackrel{\infty}{\infty}\end{array}$ & 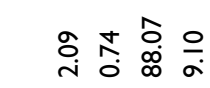 \\
\hline 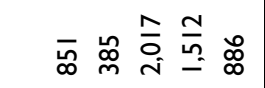 & 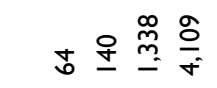 & 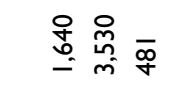 & స్ & 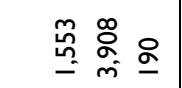 & 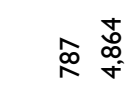 & $\stackrel{\infty}{=} \approx \underset{\sigma}{\hat{\sigma}} \frac{\tilde{\sigma}}{n}$ \\
\hline $\begin{array}{l}\frac{*}{*} \\
\frac{*}{8} \\
\stackrel{0}{\mathbf{v}} \\
\end{array}$ & 今. & $\begin{array}{l}\frac{*}{*} \\
\frac{\text { * }}{8} \\
\text { v }\end{array}$ & 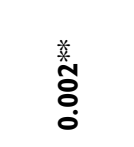 & 苂 & 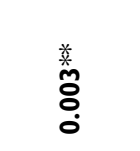 & $\begin{array}{l}\text { * } \\
\stackrel{+}{\delta} \\
\stackrel{0}{0}\end{array}$ \\
\hline 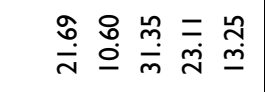 & 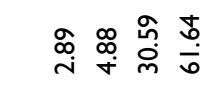 & 勇守 & 蒿 号 & 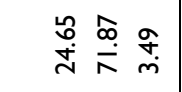 & 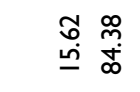 & 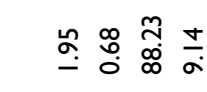 \\
\hline 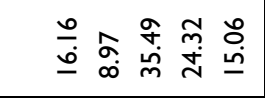 & 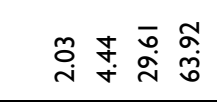 & 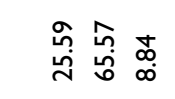 & 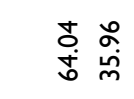 & 宔 & ¿ั & त्र \\
\hline 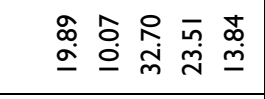 & 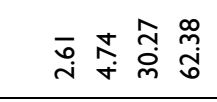 & స̦̣ & 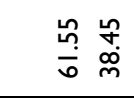 & 容 & 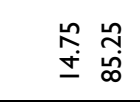 & \& \\
\hline 导 & 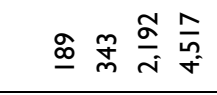 & 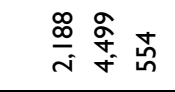 & 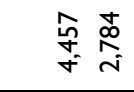 & 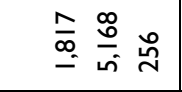 & 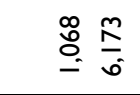 & 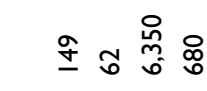 \\
\hline 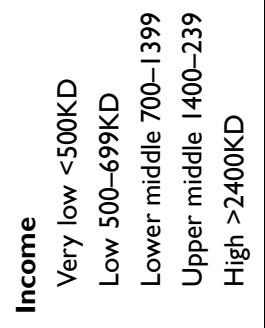 & 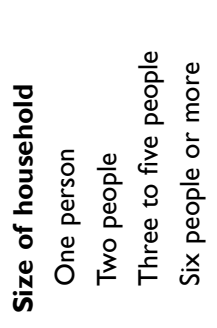 & 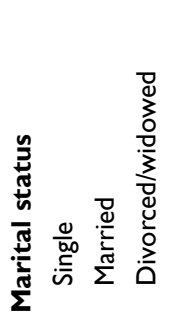 & 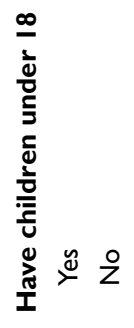 & 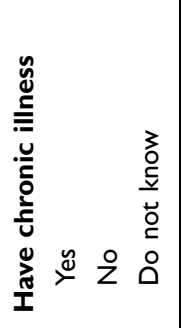 & 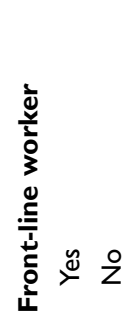 & 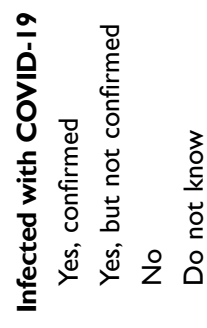 \\
\hline
\end{tabular}




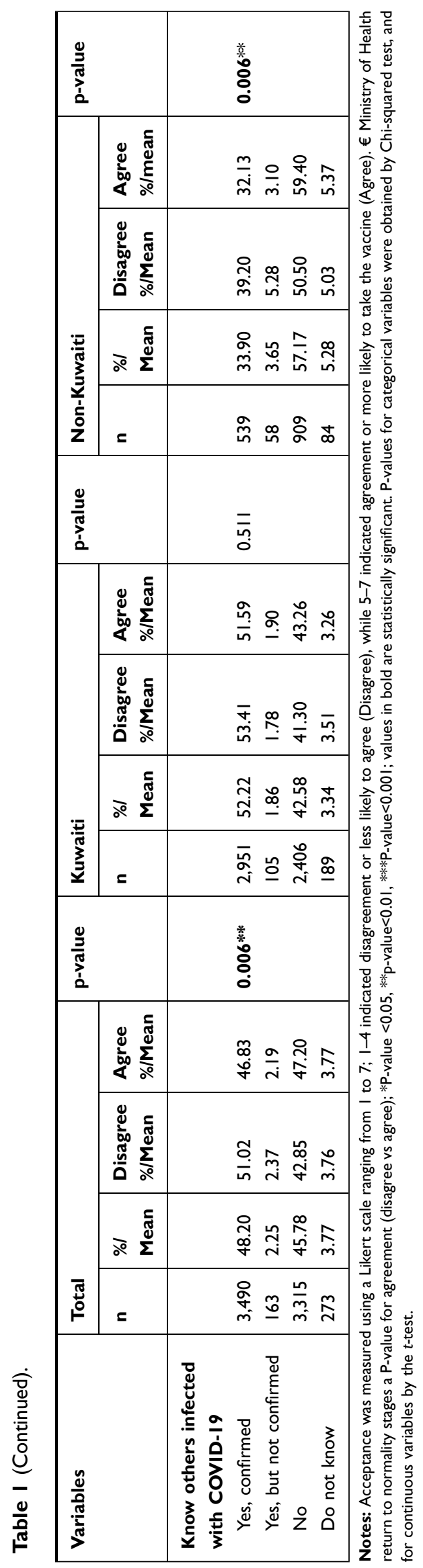

preventive measures were assigned a score of 1 each. Panic was measured using three questions on panic buying (bought extra medications, food and disinfectants on a larger scale) and five questions on behaviors (avoided people from certain countries, social events, visited family, asked the family not to visit and decided child could not meet with friends) (Cronbach $\alpha$ 0.7). Participants who responded with "already did that" or "plan to do that" were assigned a score of 1 . Mean scores within each predictor category were averaged for each participant and then scaled up to $1-7$, to ease comparisons, as per the COSMO protocol. ${ }^{16}$ Seven questions on fears (Cronbach $\alpha$ 0.7) were also included (worrying about losing someone, Health System overloading, small companies running out of business, recession, restricted food supplies, egoism, and becoming unemployed). Questions were measured on a scale from 1-7, where 1 indicated "don't worry at all" and 7 "worry a lot". The mean of the 7 responses was calculated to reflect the participants' overall fears and worries. The complete survey questions used have been published elsewhere. ${ }^{16}$

\section{Analysis}

The chi-square test, chi-square test for trend and $t$-test were used to assess the statistical significance of the COVID-19 vaccine acceptance (disagree vs agree) with categorical, ordinal and continuous variables, respectively. Two multivariable logistic regression models were performed by nationality (Kuwaiti/non-Kuwaiti), using the backward elimination method to identify factors related to people agreeing to take the vaccine (dependent variable). Univariate analyses were used to assess the magnitudes of the associations between the independent and dependent variables. Only independent predictors with p-value $<0.01$ were included in the model. All logistic regression models adhered to the goodness-of-fit test (p-value $>0.05$ ) and analyses were conducted using STATA software (StataCorp LP, Texas, USA).

\section{Results}

A total of 7241 adults participated in this study, of which $72.7 \%$ were female, and $78 \%$ were Kuwaiti (Table 1). Kuwaitis and non-Kuwaitis (non-citizens) had relatively the same age ( 38.3 vs 37.2 years). The majority of the participants were 30-44 years old (41\%), lived in the Hawalli governorate $(35 \%)$, attained a university degree (72\%), had lower-middle income 


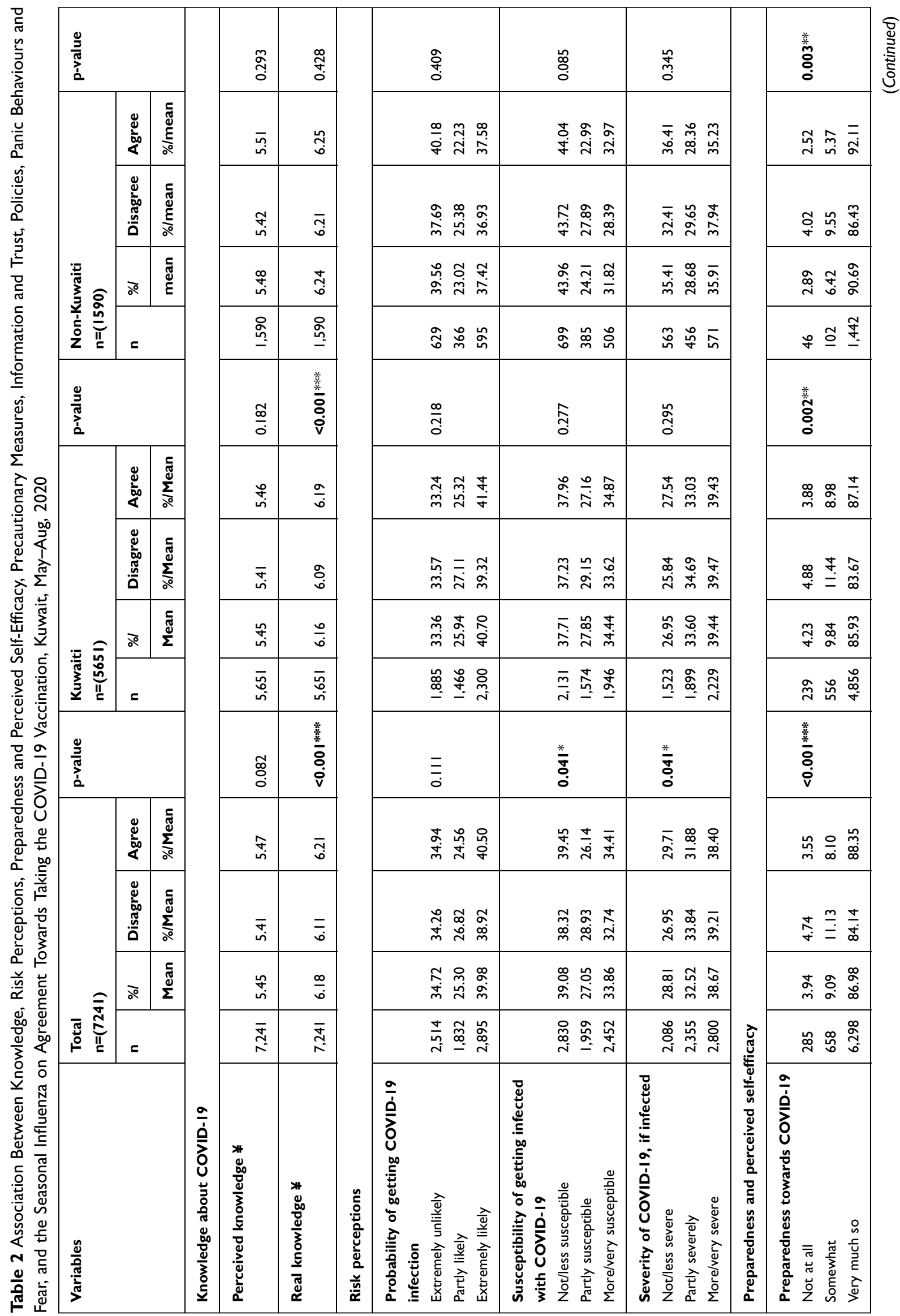




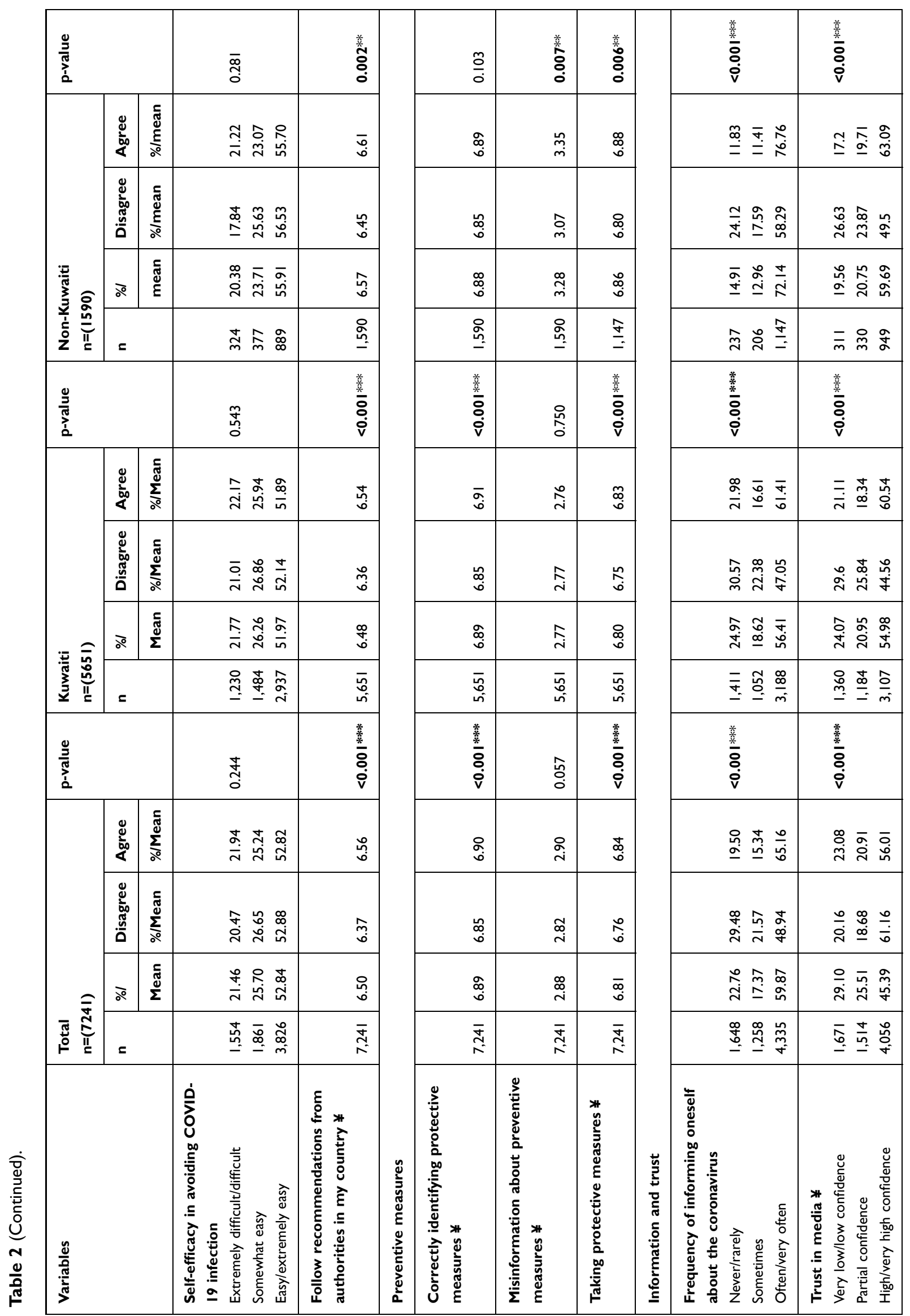




\begin{tabular}{|c|c|c|c|c|c|c|c|c|c|c|c|}
\hline 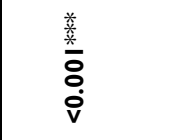 & $\begin{array}{l}\frac{\text { 妾 }}{8} \\
\dot{0} \\
\dot{v}\end{array}$ & $\begin{array}{l}\frac{.}{*} \\
\frac{1}{8} \\
\dot{0} \\
\dot{v}\end{array}$ & & $\begin{array}{l}\frac{.}{3} \\
\frac{3}{8} \\
\dot{0} \\
\dot{v}\end{array}$ & $\begin{array}{l}\text { 菨 } \\
\overline{8} \\
\dot{0} \\
\dot{v}\end{array}$ & $\begin{array}{l}\text { 㳯 } \\
\bar{\delta} \\
\dot{0}\end{array}$ & 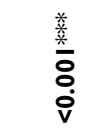 & $\begin{array}{l}\text { 恙 } \\
\overline{8} \\
\dot{0} \\
\dot{0}\end{array}$ & & 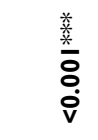 & $\begin{array}{l}\text {.. } \\
\stackrel{\circ}{\circ} \\
0 \\
0\end{array}$ \\
\hline 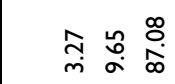 & $\underset{\infty}{\infty} \underset{\infty}{\stackrel{\infty}{\dot{x}}} \frac{\bar{\infty}}{i}$ & $\stackrel{m}{\stackrel{m}{\sim}} \stackrel{\bar{o}}{\stackrel{0}{\circ}} \stackrel{\circ}{\infty}$ & & $\stackrel{\infty}{\stackrel{\infty}{\sim}}$ & 卢 & hึ & $\bar{\sigma}$ & 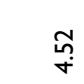 & & $\underset{\sim}{\mathbb{m}}$ & ơ \\
\hline 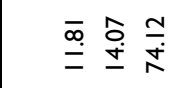 & 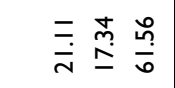 & 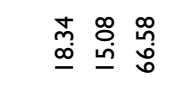 & & $\overline{\bar{m}}$ & $\underset{\substack{\alpha \\
+}}{+}$ & $\stackrel{\circ}{\stackrel{\sigma}{*}}$ & 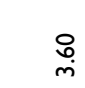 & $\underset{\leftarrow}{\stackrel{\text { f }}{ }}$ & & $\stackrel{\sim}{i}$ & $\underset{\substack{\infty \\
i n}}{ }$ \\
\hline 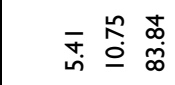 & 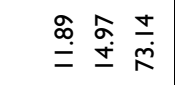 & 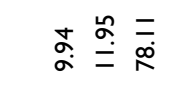 & & $\stackrel{\widehat{\infty}}{\underset{\sim}{N}}$ & $\underset{\text { ల్ }}{\tilde{n}}$ & $\underset{\text { m. }}{\bar{m}}$ & $\underset{\dot{m}}{\bar{m}}$ & 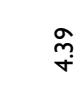 & & $\overline{\bar{m}}$ & $\underset{0}{ \pm}$ \\
\hline$\infty \Sigma \stackrel{m}{=}$ & $\stackrel{\infty}{\underline{\infty}} \stackrel{\infty}{\sim} \stackrel{\underline{0}}{=}$ & $\stackrel{\infty}{\underline{\rho}} \stackrel{\underline{f}}{\stackrel{f}{=}}$ & & 总 & 吕 & 吕 & 吕 & 只 & & 哭 & 总 \\
\hline $\begin{array}{l}\frac{.0}{*} \\
\overline{8} \\
\dot{0} \\
\dot{v}\end{array}$ & 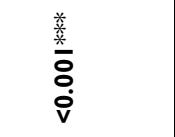 & $\begin{array}{l}\frac{.}{3} \\
\frac{1}{2} \\
\dot{0} \\
\dot{v}\end{array}$ & & $\begin{array}{l}\text { 善 } \\
\frac{0}{0} \\
\dot{0}\end{array}$ & $\begin{array}{l}\frac{.}{3} \\
\overline{8} \\
\dot{0} \\
\dot{0}\end{array}$ & $\begin{array}{l}\frac{.0}{3} \\
\frac{0}{0} \\
\dot{0}\end{array}$ & $\begin{array}{l}\text { is } \\
\frac{*}{8} \\
\dot{0} \\
\dot{v}\end{array}$ & $\begin{array}{l}\text { 觪 } \\
\dot{0} \\
\dot{0}\end{array}$ & & 吕 & $\begin{array}{l}\frac{.}{0} \\
\frac{0}{0} \\
0\end{array}$ \\
\hline 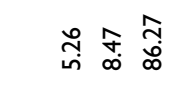 & $\begin{array}{l}\stackrel{f}{\stackrel{f}{j}} \\
\underline{\underline{j}}\end{array}$ & 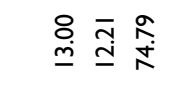 & & $\stackrel{\infty}{i}$ & $\stackrel{\sim}{\text { ح̂ }}$ & $\frac{\infty}{\dot{n}}$ & $\stackrel{+}{t}$ & 㝒 & & $\stackrel{\hat{i}}{ }$ & $\overline{0}$ \\
\hline 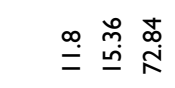 & 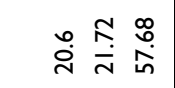 & 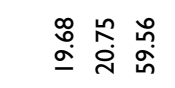 & & 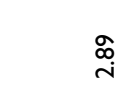 & $\underset{\substack{\infty \\
\stackrel{\infty}{+}}}{ }$ & 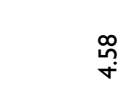 & $\stackrel{f}{f}$ & $\stackrel{\infty}{\forall}$ & & $\stackrel{\widehat{\sigma}}{\mathrm{i}}$ & $\stackrel{\infty}{\stackrel{\infty}{\circ}}$ \\
\hline 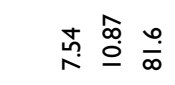 & 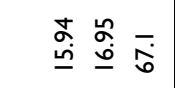 & 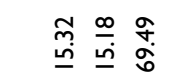 & & $\stackrel{ \pm}{\stackrel{\sim}{N}}$ & $\frac{N}{i n}$ & $\underset{\sigma}{a}$ & $\underset{\substack{n \\
+}}{+}$ & $\stackrel{F}{*}$ & & 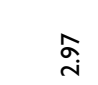 & $\stackrel{0}{i}$ \\
\hline 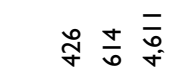 & $\bar{\alpha} \underset{\alpha}{\infty} \underset{\alpha}{\alpha}$ & 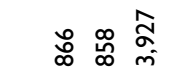 & & 氮 & 艿 & 艿 & 至 & $\begin{array}{l}\overline{3} \\
\dot{0} \\
\dot{n}\end{array}$ & & $\begin{array}{l}\overline{3} \\
\dot{0} \\
i\end{array}$ & $\begin{array}{l}\bar{n} \\
\dot{\infty} \\
\dot{n}\end{array}$ \\
\hline $\begin{array}{l}\text { w } \\
0 \\
\dot{0} \\
\dot{0}\end{array}$ & $\begin{array}{l}\frac{}{4} \\
\frac{*}{0} \\
\dot{0} \\
\dot{v}\end{array}$ & $\begin{array}{l}\frac{*}{*} \\
\frac{*}{0} \\
\dot{0} \\
\dot{0}\end{array}$ & & $\begin{array}{l}\frac{1}{6} \\
\frac{0}{0} \\
\dot{v}\end{array}$ & $\begin{array}{l}\text { 粪 } \\
0 \\
0 \\
\dot{0}\end{array}$ & $\begin{array}{l}\frac{}{*} \\
\frac{6}{0} \\
\dot{v}\end{array}$ & $\begin{array}{l}\text { v } \\
\frac{6}{0} \\
\dot{0}\end{array}$ & $\begin{array}{l}\text { : } \\
\frac{6}{8} \\
\dot{0} \\
\dot{v}\end{array}$ & & ồ & $\begin{array}{l}\frac{1}{6} \\
\frac{0}{0} \\
\dot{v}\end{array}$ \\
\hline 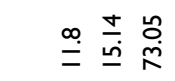 & 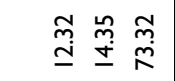 & 息离 莕 & & $\stackrel{\text { J }}{\text { ju }}$ & ભ & $\underset{\text { ஸ̊ }}{\text { ஸे }}$ & 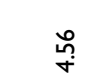 & 菅 & & $\stackrel{m}{\mathscr{m}_{n}}$ & $\overline{0}$ \\
\hline 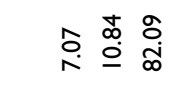 & 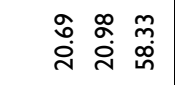 & 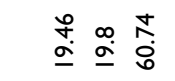 & & $\stackrel{\sim}{\sigma}$ & 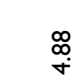 & $\underset{+}{\sigma}$ & $\underset{ণ}{\text { ণิ }}$ & $\stackrel{\underline{n}}{\dot{*}}$ & & ذ્ّ & ๙̊ำ \\
\hline 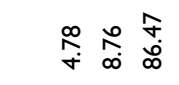 & 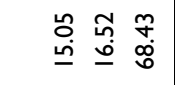 & 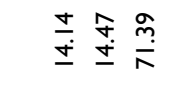 & & 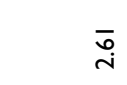 & in & 台 & $\underset{f}{f}$ & $\underset{f}{f}$ & & 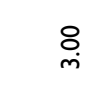 & $\stackrel{\circ}{\circ}$ \\
\hline 公怘志 & 号。资 & 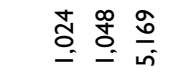 & & 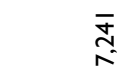 & $\underset{N}{\mathbb{N}}$ & 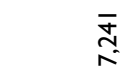 & $\underset{ }{\stackrel{\Sigma}{N}}$ & 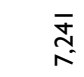 & & $\underset{ }{\mathbb{N}}$ & $\underset{\sim}{\stackrel{\Sigma}{N}}$ \\
\hline 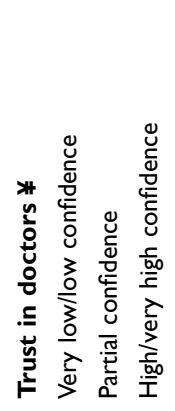 & 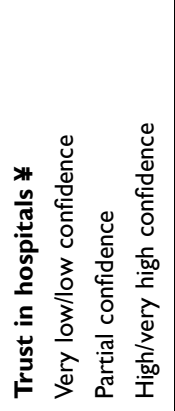 & 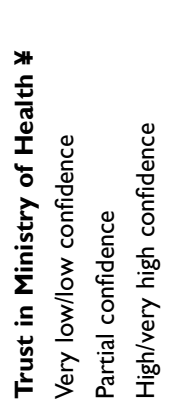 & 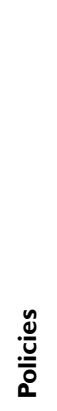 & 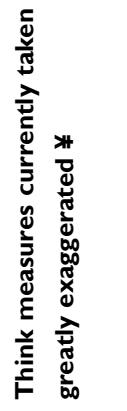 & 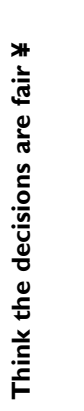 & 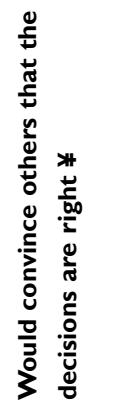 & 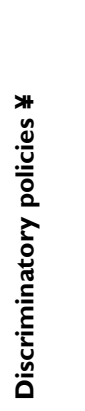 & 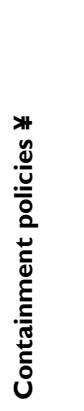 & 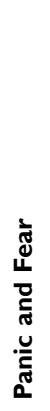 & 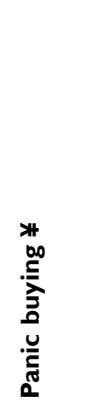 & 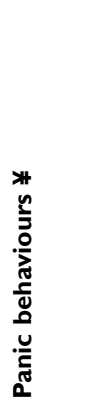 \\
\hline
\end{tabular}




\begin{tabular}{|c|c|c|c|c|c|c|c|c|c|}
\hline \multicolumn{3}{|l|}{ 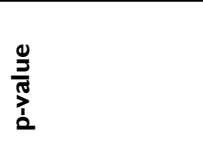 } & $\begin{array}{l}\frac{\text { 菨 }}{8} \\
\dot{8} \\
\dot{0}\end{array}$ & & $\begin{array}{l}\text { 苂 } \\
\stackrel{\tilde{O}}{0} \\
0\end{array}$ & 角 & ํㅗㅇ. & $\begin{array}{l}\text { 盖 } \\
\stackrel{0}{0} \\
0\end{array}$ & 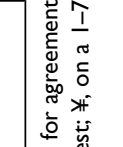 \\
\hline \multirow{4}{*}{ 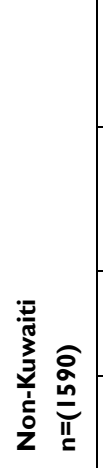 } & 离 & हू & 竎 & & 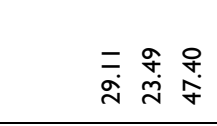 & 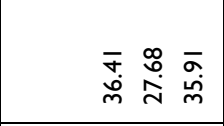 & 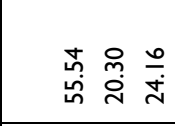 & 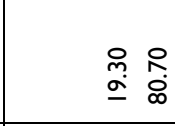 & 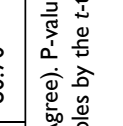 \\
\hline & 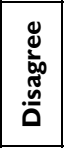 & हूँ & $\frac{m}{i n}$ & & 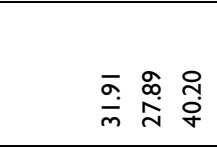 & 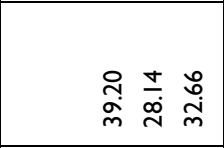 & 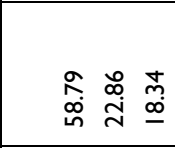 & $\begin{array}{ll}\hat{0} & \mathfrak{a} \\
\stackrel{m}{\dot{m}} & \infty\end{array}$ & 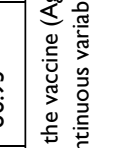 \\
\hline & ১े & ๕ึ & $\stackrel{\text { m̊ }}{\text { ì }}$ & & 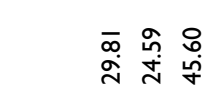 & 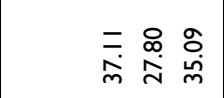 & 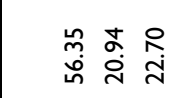 & 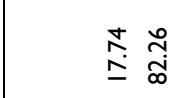 & 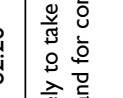 \\
\hline & $=$ & & 용 & & 奇可芳 & 品 导 串 & 今 & $\stackrel{\text { D }}{\stackrel{\infty}{m}}$ & 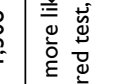 \\
\hline \multicolumn{3}{|l|}{ 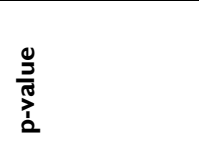 } & 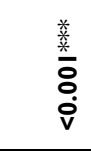 & & $\begin{array}{l}\frac{.}{10} \\
\bar{\vdots} \\
\dot{0} \\
\mathbf{v}\end{array}$ & $\begin{array}{l}\frac{}{*} \\
\bar{s} \\
\dot{0} \\
\dot{v}\end{array}$ & $\begin{array}{l}\stackrel{*}{\hat{N}} \\
\stackrel{0}{0} \\
0 \\
0\end{array}$ & $\begin{array}{l}\frac{}{*} \\
\overline{8} \\
\dot{0} \\
\dot{v}\end{array}$ & 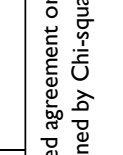 \\
\hline \multirow{4}{*}{ 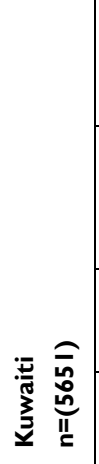 } & 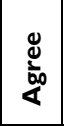 & 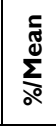 & $\stackrel{+}{a}$ & & $\begin{array}{l}\stackrel{\circ}{\circ} \\
\stackrel{\sim}{\sim}\end{array}$ & 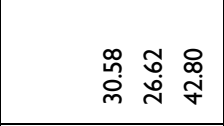 & 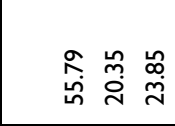 & $\begin{array}{l}\hat{n} \\
\underline{\infty} \\
\stackrel{f}{\infty}\end{array}$ & 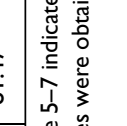 \\
\hline & 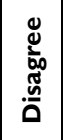 & 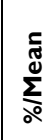 & 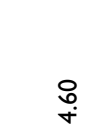 & & 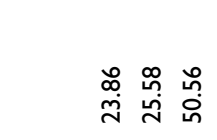 & 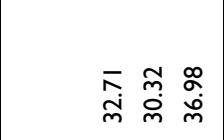 & î̀ & $\stackrel{\circ}{\stackrel{\circ}{=}}$ & 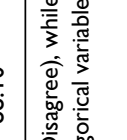 \\
\hline & ১о & $\underset{\mathbf{\Phi}}{\mathbf{\Sigma}}$ & $\underset{+}{i}$ & & 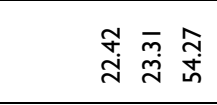 & $\stackrel{\tilde{m}}{\bar{m}} \underset{\bar{\alpha}}{\stackrel{i}{\alpha}}$ & $\begin{array}{l}\bar{m} \\
\stackrel{\infty}{\circ} \stackrel{\infty}{\sim} \\
\stackrel{\sim}{\sim}\end{array}$ & 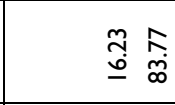 & 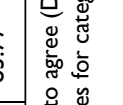 \\
\hline & $=$ & & $\begin{array}{l}\bar{n} \\
\text { in } \\
\text { in }\end{array}$ & & 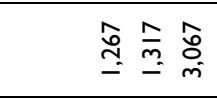 & 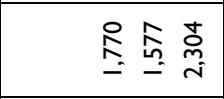 & 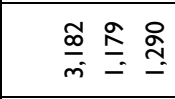 & 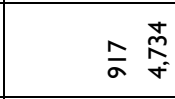 & 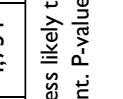 \\
\hline \multicolumn{3}{|l|}{ 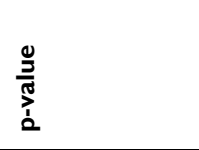 } & $\begin{array}{l}\frac{*}{*} \\
0 \\
\dot{0} \\
\dot{0}\end{array}$ & & $\begin{array}{l}\frac{*}{*} \\
\frac{*}{*} \\
\dot{0} \\
\dot{0}\end{array}$ & $\begin{array}{l}\frac{}{4} \\
\frac{1}{*} \\
\dot{0} \\
\dot{v}\end{array}$ & 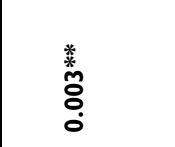 & $\begin{array}{l}\frac{*}{*} \\
\frac{*}{8} \\
\dot{0} \\
\mathbf{v}\end{array}$ & 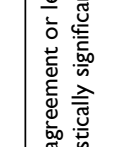 \\
\hline \multirow{4}{*}{ 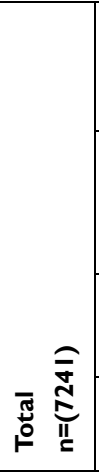 } & 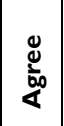 & $\sum_{\substack{0 \\
\delta}}^{\frac{5}{0}}$ & 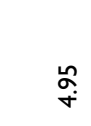 & & 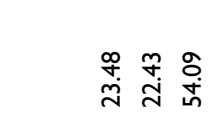 & 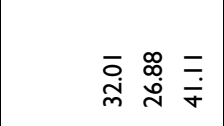 & 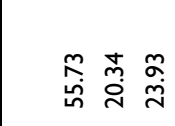 & $\begin{array}{ll}N & \infty \\
\stackrel{\sim}{\infty} & \stackrel{\infty}{\infty}\end{array}$ & 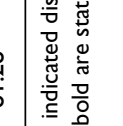 \\
\hline & 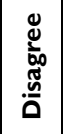 & 离 & $\underset{\sigma}{\stackrel{a}{+}}$ & & 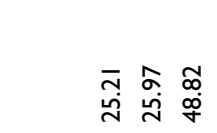 & 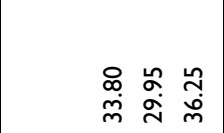 & 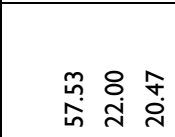 & 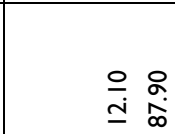 & $\frac{0}{\frac{0}{5}}$ \\
\hline & ๖ั & $\underset{\mathbf{\Phi}}{\mathbf{\Sigma}}$ & $\stackrel{\circ}{\stackrel{\infty}{+}}$ & & 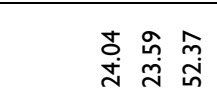 & 总 & 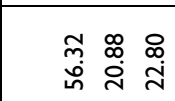 & 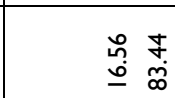 & 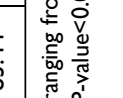 \\
\hline & $=$ & & 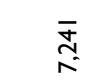 & & 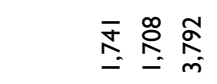 & 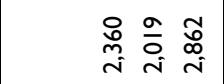 & 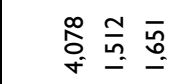 & $\begin{array}{l}\sigma \\
\stackrel{0}{0} \\
=\end{array}$ & 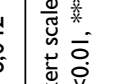 \\
\hline & 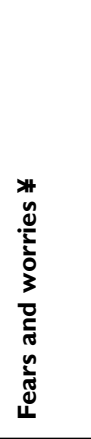 & 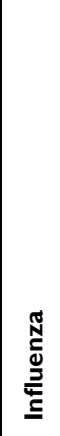 & 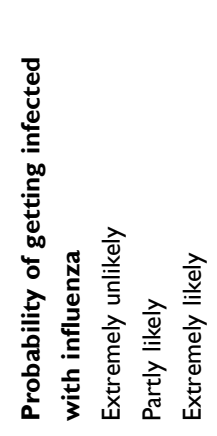 & 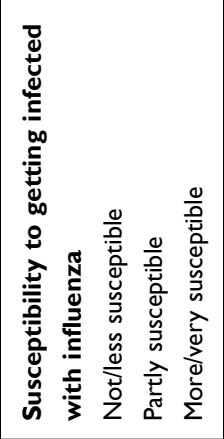 & 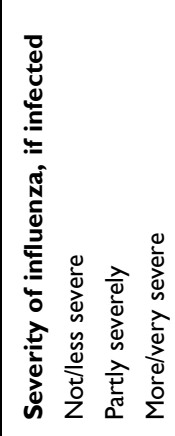 & 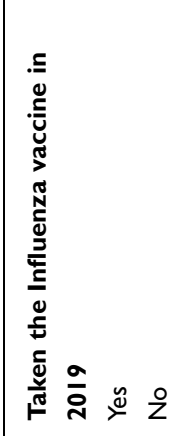 & 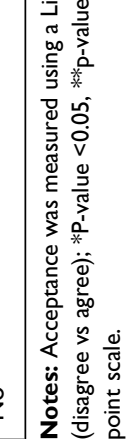 \\
\hline
\end{tabular}


level $(32.7 \%)$, lived in a household with six people or more $(62 \%)$, were married $(62 \%)$, with children under 18 years of age $(62 \%)$, did not have any chronic illnesses $(71 \%)$, were not front-line workers $(85 \%)$, and were infected with COVID-19 (89\%). About half, however, reported knowing others that were confirmed as having COVID-19 (48.2\%).

There was a significant decline over time, in the population's mean level of COVID-19 vaccine acceptance between the stage of complete lockdown to stage 4 of the $\mathrm{MOH}$ return to normality plan; mean acceptance decreased from 5.9 to 4.9 and 5.5 to 4.1 among Kuwaitis and non-Kuwaitis, respectively (Figure 2). The proportion of agreement to take the vaccine dropped from $73 \%$ to $47 \%$ among Kuwaitis, and $80 \%$ to $60 \%$ among nonKuwaitis, between complete lockdown and stage 4 (Figure 3). Across all stages, more non-Kuwaitis agreed to take the vaccine than Kuwaitis; however, differences were only statistically significant during the complete lockdown stage, stage 3, and stage 4 .

A total of $67 \%$ agreed to take the COVID-19 vaccine if it was available and recommended in the country; $75 \%$ non-Kuwaitis and $65 \%$ Kuwaitis (Table 1). Sociodemographic characteristics related to significantly greater agreement than disagreement $(\mathrm{p}<0.05)$ included being male (30 vs $22 \%$ ), ages $18-29$ years (31 vs $23 \%$ ), an education level of high school or less (10 vs 7\%), a very low (22 vs 16\%) and low (11 vs 9\%) income, being single (33 vs 26\%), front-line workers (16 vs $13 \%$ ), not having had an infection with the coronavirus ( 88 vs $87 \%$ ), and not knowing others infected (47 vs $43 \%$ ).

Among the total population, other predictors (Table 2) that were statistically higher $(\mathrm{p}<0.001)$ among participants who agreed to take the vaccine included knowledge of COVID-19, the perception of being prepared to protect oneself, following recommendations from authorities, correctly identifying protective measures, taking protective measures, informing oneself about the coronavirus, having high confidence in the media, doctors, hospitals or the Ministry of Health, believing that the government decisions are fair, the likelihood of convincing others that the decisions are right, agreeing with discriminatory and containment policies, engaging in more panic behaviors, expressing fears and worries, perceiving the probability and susceptibility to the season influenza infection as extremely likely, and taking the influenza vaccine in 2019.

Stratified univariate analyses indicated that risk perceptions towards the coronavirus (the probability, susceptibility and perceived severity of the coronavirus infection) were not statistically associated to vaccine acceptance among Kuwaitis or non-Kuwaitis (Table 2). The analyses also indicated that factors associated with vaccine

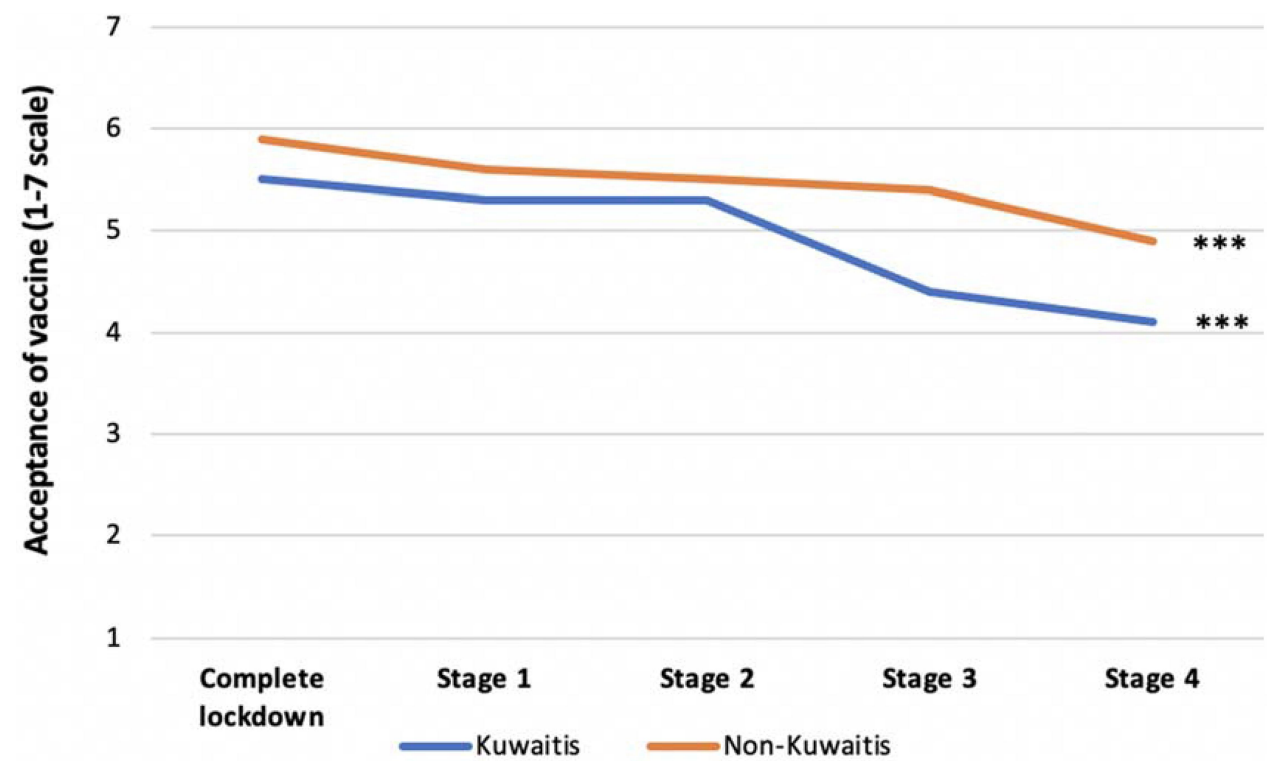

Figure 2 The mean level of acceptance to taking the COVID-19 vaccine if it becomes available and recommended, by nationality (Kuwaiti, non-Kuwaiti), during the Ministry of Health's "Return to Normality" stages, Kuwait, May-Aug 2020.

Notes: Acceptance measured using a Likert scale ranging from I to 7 , with I indicating strongly disagree and 7 strongly agree; $* * * i n d i c a t e s$ a significant $(\mathrm{P}<0.00 \mathrm{I})$ trend observed in the mean acceptance level overtime time (stages). 


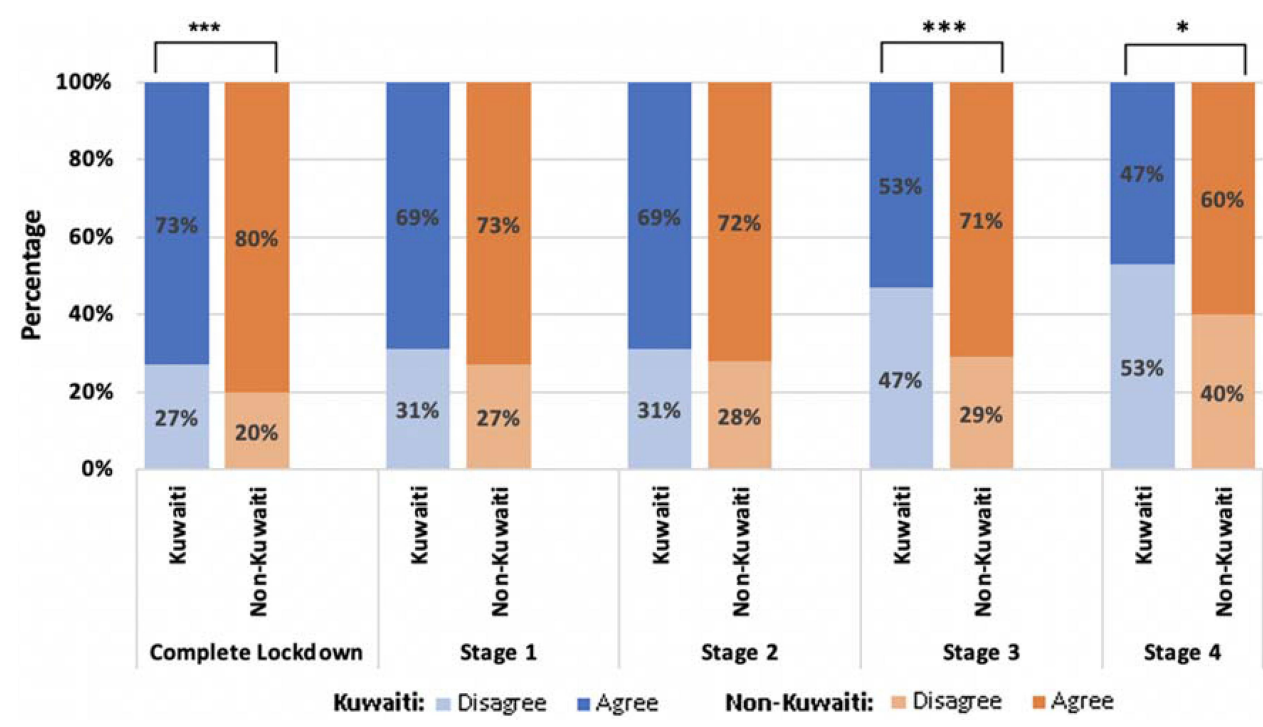

Figure 3 The proportion of agreement and disagreement towards taking the COVID-19 vaccine across the Ministry's "Return to normality" stages, by nationality (Kuwaiti, non-Kuwaiti), Kuwait, May-Aug 2020.

Notes: Acceptance was measured using a Likert scale ranging from I to 7; I-4 indicated disagreement or less likely to agree (Disagree), while 5-7 indicated agreement or more likely to take the vaccine (Agree). Vaccine acceptance (disagree/agree) was statistically significantly associated across stages, in Kuwaitis and non-Kuwaitis $\left(P_{\text {trend }}<0.00 \mathrm{I}\right)$; $\mathrm{P}$-values for statistical association between vaccine acceptance and nationality (Kuwaiti/non-Kuwaiti) obtained by Chi-squared test, ${ }^{*} \mathrm{P}-\mathrm{value}<0.05$, $* *$ p-value $<0.01$, ***P-value $<0.001$

acceptance were generally similar among Kuwaitis and non-Kuwaitis; However, among non-Kuwaitis, engaging in more panic buying behaviors was associated with vaccine agreement, as was having greater misinformation about the coronavirus protective measures $(\mathrm{p}<0.001$ and $\mathrm{p}<0.01$, respectively).

Multivariable regression analyses (Table 3) indicated that factors significantly associated with increased odds of agreeing to take the COVID-19 vaccine among Kuwaitis and non-Kuwaitis, included informing oneself about the coronavirus (OR, 1.34-1.83; 95\% CI 1.16-2.55), having high or very high confidence in doctors (OR, 1.79-2.11; 95\% CI 1.17-3.80), having a higher agreement with containment policies (OR, 1.11-1.27, 95\% CI 1.05-1.41), expressing more fears and worries (OR, 1.05-1.12; 95\% CI 1.01-1.24), and perceiving the probability of getting infected with seasonal influenza as extremely likely (OR, $1.33-1.38$; $95 \%$ CI $1.03-1.84)$. Contrarily, factors associated with decreased odds of vaccine agreement were increased age (OR, 0.37-0.61; 95\% CI 0.26-0.95), being female (OR, 0.56-0.62; 95\% CI 0.43-0.73), an increased belief that the measures taken are greatly exaggerated (OR, 0.91-0.95; 95\% CI 0.86-0.98), and not taking the seasonal influenza vaccine in 2019 (OR, 0.61; 95\% CI 0.43-0.87).

Among Kuwaitis, increased odds of vaccine agreement were also associated with higher levels of real knowledge regarding COVID-19 (OR, 1.12; 95\% CI 1.05-1.20), greater adherence to recommendations from authorities (OR, 1.08; 95\% CI 1.01-1.16), correctly identifying more protective measures (OR, 1.26; 95\% CI 1.09-1.47), having high/very high confidence in the media compared to those with low/very low confidence (OR, 1.32; 95\% CI $1.12-1.56)$, increased likelihood of convincing others that the decisions taken by the country are right (OR, 1.09; 95\% CI 1.06-1.13), and increased agreement with discriminatory policies (OR, 1.09; 95\% CI 1.04-1.14) (Table 3). However, being married or divorced/widowed was associated with lower odds of agreement (OR, 0.77; 95\% CI $0.60-0.92)$. Among non-Kuwaitis, additional factors associated with increased agreement included the perception of being very well protected towards COVID-19 compared to not being prepared at all (OR, 1.78; 95\% CI 0.90-3.53), having high/very high confidence in the country's hospitals compared to those with low or very low confidence (OR, 1.76; 95\% CI 1.13-2.72), and higher engagement in panic-buying behaviors during the pandemic (OR, 1.09; 95\% CI 1.03-1.16).

\section{Discussion}

To our knowledge, this is the only study that has monitored and quantified the potential COVID-19 vaccination acceptance overtime during the pandemic in Kuwait using a large sample size of citizens and non-citizens. Understanding 
Table 3 Multivariable analysis: Factors Related to Increased Agreement Towards Taking the COVID Vaccine, by Nationality (Kuwaiti/ Non-Kuwaiti), Kuwait, May-September, 2020

\begin{tabular}{|c|c|c|c|c|c|c|}
\hline \multirow[t]{3}{*}{ Characteristic } & \multicolumn{6}{|c|}{ Agree to Take the COVID Vaccine } \\
\hline & \multicolumn{3}{|c|}{ Kuwaiti $(n=565 I)$} & \multicolumn{3}{|c|}{ Non-Kuwaiti $(n=1590)$} \\
\hline & OR & $(95 \% \mathrm{Cl})$ & p-value & OR & $(95 \% \mathrm{Cl})$ & p-value \\
\hline \multicolumn{7}{|l|}{ Stage } \\
\hline Complete lockdown & [reference] & & & & & \\
\hline Stage 1 & 0.80 & $(0.67-0.95)$ & $0.010^{*}$ & & & \\
\hline Stage 2 & 0.80 & $(0.67-0.96)$ & $0.017^{*}$ & & & \\
\hline Stage 3 & 0.50 & $(0.40-0.61)$ & $0.000 * *$ & & & \\
\hline Stage 4 & 0.35 & $(0.28-0.43)$ & $<0.001 * * *$ & & & \\
\hline \multicolumn{7}{|l|}{ Age (years) } \\
\hline 18-29 & [reference] & & & [reference] & & \\
\hline $30-44$ & 0.62 & $(0.52-0.74)$ & $<0.001 * * *$ & 0.79 & $(0.59-1.06)$ & 0.120 \\
\hline $45-59$ & 0.52 & $(0.42-0.64)$ & $<0.001^{* * *}$ & 0.61 & $(0.44-0.87)$ & $0.005^{* *}$ \\
\hline $60-74$ & 0.37 & $(0.28-0.49)$ & $<0.00 I^{* * * *}$ & 0.50 & $(0.26-0.95)$ & $0.034^{*}$ \\
\hline \multicolumn{7}{|l|}{ Gender } \\
\hline Male & [reference] & & & [reference] & & \\
\hline Female & 0.62 & $(0.53-0.72)$ & $<0.00 I^{* * * *}$ & 0.56 & $(0.43-0.73)$ & $<0.00 I^{* * *}$ \\
\hline \multicolumn{7}{|l|}{ Marital } \\
\hline Single & [reference] & & & & & \\
\hline Married & 0.77 & $(0.65-0.92)$ & $0.004^{* *}$ & & & \\
\hline Divorced/widowed & 0.77 & $(0.60-0.99)$ & $0.043 *$ & & & \\
\hline \multicolumn{7}{|l|}{ Real knowledge $¥$} \\
\hline & 1.12 & $(1.05-1.20)$ & $0.001 * *$ & & & \\
\hline \multicolumn{7}{|c|}{$\begin{array}{l}\text { Follow recommendations from authorities in my } \\
\text { country } ¥\end{array}$} \\
\hline & 1.08 & $(1.01-1.16)$ & $0.029 *$ & & & \\
\hline \multicolumn{7}{|c|}{ Preparedness towards COVID-19 } \\
\hline Not at all & & & & [reference] & & \\
\hline Somewhat & & & & 1.11 & $(0.50-2.47)$ & 0.807 \\
\hline Very much so & & & & 1.78 & $(0.90-3.53)$ & 0.099 \\
\hline \multicolumn{7}{|c|}{ Correctly identifying protective measures $¥$} \\
\hline & 1.26 & $(1.09-1.47)$ & $0.002 * *$ & & & \\
\hline \multicolumn{7}{|c|}{ Frequency of informing oneself about the coronavirus } \\
\hline Never/rarely & [reference] & & & [reference] & & \\
\hline Sometimes & 0.99 & $(0.83-1.18)$ & 0.925 & 1.11 & $(0.73-1.68)$ & $0.637 * * *$ \\
\hline Often/very often & 1.34 & $(1.16-1.55)$ & $<0.001$ & 1.83 & $(1.32-2.55)$ & $<0.001$ \\
\hline \multicolumn{7}{|l|}{ Trust in media $¥$} \\
\hline Very low/low confidence & & & & [reference] & & \\
\hline Partial confidence & 0.87 & $(0.73-1.04)$ & 0.123 & & & \\
\hline High/very high confidence & 1.32 & $(1.12-1.56)$ & $0.00 I^{* *}$ & & & \\
\hline \multicolumn{7}{|l|}{ Trust in doctors $¥$} \\
\hline Very low/low confidence & [reference] & & & [reference] & & \\
\hline Partial confidence & 1.20 & $(0.91-1.59)$ & 0.192 & 1.76 & $(0.93-3.34)$ & $0.085 *$ \\
\hline High/very high confidence & 1.79 & $(1.41-2.27)$ & $0.000 * *$ & 2.11 & $(1.17-3.80)$ & 0.013 \\
\hline
\end{tabular}

(Continued) 
Table 3 (Continued).

\begin{tabular}{|c|c|c|c|c|c|c|}
\hline \multirow[t]{3}{*}{ Characteristic } & \multicolumn{6}{|c|}{ Agree to Take the COVID Vaccine } \\
\hline & \multicolumn{3}{|c|}{ Kuwaiti (n=565I) } & \multicolumn{3}{|c|}{ Non-Kuwaiti $(n=1590)$} \\
\hline & OR & $(95 \% \mathrm{Cl})$ & p-value & OR & $(95 \% \mathrm{Cl})$ & p-value \\
\hline $\begin{array}{l}\text { Trust in hospitals } ¥ \\
\text { Very low/low confidence } \\
\text { Partial confidence } \\
\text { High/very high confidence }\end{array}$ & & & & $\begin{array}{l}\text { [reference] } \\
1.58 \\
1.76\end{array}$ & $\begin{array}{l}(0.97-2.58) \\
(1.13-2.72)\end{array}$ & $\begin{array}{l}0.066^{*} \\
0.012\end{array}$ \\
\hline Think measures currently taken greatly exaggerated $¥$ & 0.95 & $(0.92-0.98)$ & 0.001 & 0.91 & $(0.86-0.97)$ & $0.003^{* *}$ \\
\hline Think the decisions are fair $¥$ & & & & 1.08 & $(1.01-1.16)$ & $0.032 *$ \\
\hline Would convince others that the decisions are right $¥$ & 1.09 & $(1.06-1.13)$ & $<0.001 * * *$ & & & \\
\hline Discriminatory policies $¥$ & 1.09 & $(1.04-1.14)$ & $<0.00 \mathrm{I}^{* * *}$ & & & \\
\hline Containment policies $¥$ & 1.11 & $(1.05-1.17)$ & $<0.001 * * *$ & 1.27 & $(1.15-1.41)$ & $<0.001^{* * *}$ \\
\hline Panic buying $¥$ & & & & 1.09 & $(1.03-1.16)$ & $0.003^{* *}$ \\
\hline Panic Behaviours $¥$ & 0.94 & $(0.90-1.00)$ & $0.004^{* *}$ & & & $* *$ \\
\hline Fears and worries $¥$ & 1.05 & $(1.00-1.10)$ & $0.039 *$ & 1.12 & $(1.01-1.24)$ & $0.034^{*}$ \\
\hline $\begin{array}{l}\text { Probability of getting infected with influenza } \\
\text { Extremely unlikely } \\
\text { Partly likely } \\
\text { Extremely likely }\end{array}$ & $\begin{array}{l}\text { [reference] } \\
1.09 \\
1.33\end{array}$ & $\begin{array}{l}(0.91-1.29) \\
(1.15-1.55)\end{array}$ & $\begin{array}{l}0.343 \\
<0.001 * * *\end{array}$ & $\begin{array}{l}\text { [reference] } \\
1.03 \\
1.38\end{array}$ & $\begin{array}{l}(0.75-1.43) \\
(1.03-1.84)\end{array}$ & $\begin{array}{l}0.839 \\
0.032^{*}\end{array}$ \\
\hline $\begin{array}{l}\text { Taken the Influenza vaccine in } 2019 \\
\text { Yes } \\
\text { No }\end{array}$ & $\begin{array}{l}\text { [reference] } \\
0.6 \mathrm{I}\end{array}$ & (0.5। 0.72$)$ & $<0.001 * * *$ & $\begin{array}{l}\text { [reference] } \\
0.61\end{array}$ & $(0.43-0.87)$ & $0.006^{* *}$ \\
\hline
\end{tabular}

Notes: ${ }^{\mathrm{p}}$-value $<0.05,{ }^{*} \mathrm{p}$-value $<0.0 \mathrm{I},{ }^{*} *{ }_{\mathrm{p}}$-value $<0.00 \mathrm{I}$; values in bold are statistically significant.

vaccine acceptance is crucial given that Kuwait has authorized emergency use of the Pfizer-BioNTech COVID-19 vaccine $^{17}$ and that return to normal life activities in the country is dependent on it. Since non-citizens in the country comprise about $70 \%$ of the population, stratification of results was necessary, allowing for more valid and representative results. Our study used data from the COSMO Kuwait study that was implemented according to the WHO tool for behavioral insights on COVID-19. ${ }^{16}$ COSMO studies were officially implemented in over ten countries, thus allowing more valid comparisons of global results to be made.
The overall acceptance of taking the vaccine in Kuwait was $67 \%$. A study conducted in 2020 to assess the COVID-19 vaccine acceptance in 19 countries, ${ }^{12}$ indicated that China had the highest acceptance (89\%), while Russia had the lowest (55\%). Compared to our results, vaccine acceptance in Kuwait was relatively similar to that in Singapore $(68 \%)$ and Indonesia $(67 \%)^{12,18}$ but higher than in Sweden (65\%), Nigeria (65\%), France $(56 \%)$, Poland (56\%) and Russia (55\%). ${ }^{12}$ Acceptance in Kuwait was, however, lower than in many countries such as Germany, Canada, Italy, UK, Spain, India, US, Mexico, South Korea, South Africa, Brazil, and China where it 
ranged from $68-89 \%{ }^{12}$ In countries for which the COSMO study was implemented, and results were published, vaccine acceptance was higher in Kuwait (71\%) than in Canada (65\%) during similar data collection periods in June. Results from COSMO Turkey indicated the mean vaccine acceptance level, on a scale from 1-7, ranged from 5.3-5.1 during July-August. Vaccine acceptance was similar to that among non-citizens during comparative dates (5.4-4.9) but higher than that among Kuwaitis (4.1-4.4). ${ }^{19}$

Coinciding with recent findings from Saudi Arabia, ${ }^{20}$ our results indicated that non-citizens had a higher proportion of vaccine acceptance (75\%) compared to citizens (65\%). Results revealed that among both citizens and non-citizens, the expression of greater fears and worries related to COVID-19 was associated with an increased likelihood of vaccine acceptance; however, the average level of fear and worries was greater among non-citizens than citizens (4.8 vs 5.4 on a 1-7 scale, respectively). Specifically, non-citizens were significantly more worried about being unemployed during the pandemic than citizens (5.0 vs 3.0 on a 1-7 scale; results not published). In the USA, employed participants had higher COVID-19 acceptance than those unemployed. ${ }^{21}$ In Australia, business companies were lobbying for powers to sanction workers who refuse the coronavirus vaccine. ${ }^{22}$ Collectively, these findings highlight the role of employment and fear of becoming unemployed as motivators for COVID-19 vaccination. Furthermore, for non-citizens, getting vaccinated could provide immunity to an infection, possibly providing individuals with greater sense of independence and security to travel abroad. Enforcing vaccination for travel purposes could therefore also be a potential stimulus to achieving greater inoculation rates, particularly in countries where the expatriate population is high.

In Kuwait, vaccine acceptance declined overtime during the pandemic and as COVID-19 related restrictions were eased in the country. Acceptance dropped from $73 \%$ to $47 \%$ among Kuwaitis and from $80 \%$ to $60 \%$ among non-Kuwaitis, over less than four months since the country's complete lockdown. This decline in vaccine acceptance since the first wave of data collection was also observed in the COSMO Turkey, Canada and Spain studies. ${ }^{19,23,24}$ In Canada, the proportion of people who disagreed with taking the vaccine doubled from $6 \%$ in April (wave 1) to $12 \%$ in June (wave 5). ${ }^{19}$ In Spain, acceptance dropped from $70 \%$ in July to only $43 \%$ in September. ${ }^{24}$ This could suggest that as countries globally continue to ease their restrictions and people become more desensitized to the virus, acceptance may further decline, potentially leading to low inoculation rates. A substantial burden will, therefore, be placed on health campaigns to promote the uptake of the COVID-19 vaccine once released.

The likelihood of getting vaccinated was higher among males in Kuwait. These findings were coincident with other studies assessing the determinants of COVID-19 vaccine acceptance. ${ }^{20,21,24,25}$ Among citizens, being married was also significantly associated with increased odds of vaccine acceptance, as shown in China ${ }^{25}$ and Saudi Arabia. $^{20}$ However, in Kuwait vaccine acceptance was more likely among younger than older adults. While these results were significant among both citizens and not citizens, they contrast with recent studies relating older age with higher vaccine acceptance. This past year, social media has heavily influenced individuals' vaccine hesitancy. Puri et al demonstrate that older adults may be more vulnerable to the narrative of vaccine hesitancy. ${ }^{26}$ This critical finding accentuates the need for effective and targeted vaccine-acceptance messages in Kuwait that targets older people who are more vulnerable and are at higher risk of getting severe COVID-19 disease.

Citizens and non-citizens with high trust in their doctors were two times more likely to get vaccinated. Having higher trust in the health system was shown to be associated with greater utilization of preventive health services such as the influenza vaccine, ${ }^{27,28}$ in addition to increased acceptance of the latent COVID-19 vaccine ${ }^{20,25}$ However, our study also revealed that among citizens, higher trust in the media was associated with an increased likelihood of vaccine acceptance. The media and social media influencers can play a crucial role in the promotion of a new vaccine. For instance, in the UK, the composer Andrew Lloyd Webber, Health Secretary Matt Hancock and Chief Medical Officer Chris Witty participated in the Oxford trial for the future vaccine and encouraged people to participate via Twitter. This led to high levels of engagement and aided the continuation of posts about coronavirus vaccine in social media, with minimal (11\%) negative content about the vaccine. ${ }^{22}$ Using local social media influencers and health professionals to advocate for inoculation can create a positive vaccine sentiment in the country, potentially encouraging citizens who are less likely to get vaccinated.

People's perceived risk of infection has been reported as a predictor of COVID-19 vaccine acceptance ${ }^{20,24,25,29,30}$ 
In our study, risk perceptions towards the coronavirus infection were not significantly related to vaccine acceptance. However, participants who perceived their probability of getting infected with seasonal influenza, as partly or extremely likely, had increased odds of getting vaccinated. Vaccination against influenza in the past season (2019) was also associated with an increased likelihood of vaccination, among both citizens and non-citizens. These results were also observed in China $^{25}$ and could suggest that the community's past experiences regarding the attainment of vaccines could either endorse or hinder the uptake of the new COVID-19 vaccine.

During the period of the study, the government had placed numerous restrictive policies in efforts to control the spread of infection. Participants were thus asked about their agreement to containment policies that restricted their personal liberty, choice of a place of residence, internet and social media access, closures of community facilities such as schools, and prohibition of e-learning. Results indicated that people who agreed more with such containment policies had increased odds of vaccine acceptance. There was also an increased likelihood of vaccine acceptance if people agreed with discriminatory behaviors such as agreeing that anyone not from Kuwait should be quarantined or sent away, and avoiding certain people based on their country of origin. The COVID-19 pandemic has been associated with many elements of social stigma and discrimination. ${ }^{31,32}$ Acquiring immunity through vaccination could potentially protect against stigmatization and discrimination of being infected with COVID-19; particularly if one expresses such discriminatory behaviors himself.

One of the main limitations of our study was that it was conducted solely using a web-based survey. As with all online surveys, minority groups and older adults in the country are generally underrepresented. Due to the nature of the pandemic and its related physical distancing obligations, online data collection was the only feasible method. However, in order to increase the representativeness of the data and improve external validity, a substantially large sample was obtained. Stratification of the data was also performed since non-citizens compromised the majority of the population in Kuwait and were underrepresented. The survey was also promoted by several diverse social media influencers, during each stage of data collection, to increase the sample's representativeness; making this study one of the first of its kinds in the country to demonstrate the people's intention to uptake the COVID19 vaccine.

\section{Conclusion}

Our results indicated that acceptance was multifactorial, heterogenous among citizens and non-citizens, and can change over time. While potential uptake of the COVID19 vaccine was high during the complete lockdown in the country, it has since steadily decreased among both citizens and non-citizens. Moving forward, further continuous declines in acceptance can lead to low inoculation levels in the country that will require the implementation of vigorous and effective vaccine-promotion campaigns. Several predictors of vaccine acceptance in the country were also addressed, and recommendations for methods to increase vaccine uptake were proposed. Findings from this study can aid healthcare professionals, health officials, and political stakeholders in developing policies related to the administration of the vaccine among citizens and noncitizens in the country. They can also support the tailoring of vaccine-acceptance messages to advocate, educate, and address concerns, especially among more vulnerable groups.

\section{Disclosure}

The authors report no conflicts of interest in this work.

\section{References}

1. The push for a COVID-19 vaccine [Internet]]. Available from: https:// www.who.int/emergencies/diseases/novel-coronavirus-2019/covid-19vaccines. Accessed November 6, 2020.

2. Zimmer C, Corum J, Wee S-L Coronavirus vaccine tracker. The New York times. 2020. Available from: https://www.nytimes.com/ interactive/2020/science/coronavirus-vaccine-tracker.html. Accessed December 19, 2020.

3. As rich countries hoard potential coronavirus vaccine doses, rest of world could go without. Washington post. Washington, DC: 1974. Available from: https://www.washingtonpost.com/world/coronavirusvaccine-doses-wealth-gap/2020/11/02/3cf7b078-1d1b-11eb-9ec33a81e23c4b5e_story.html. Accessed November 6, 2020.

4. Kuwait inks coronavirus vaccine deal with international organization. Arab news. 2020. Available from: https://www.arabnews.com/node/ 1710721/middle-east. Accessed November 6, 2020.

5. Buttenheim AM. SARS-CoV-2 vaccine acceptance: we may need to choose our battles. Ann Intern Med. 2020;4(M20-6206). doi:10.7326/M20-6206

6. Determann D, Korfage IJ, Lambooij MS, et al. Acceptance of vaccinations in pandemic outbreaks: a discrete choice experiment. PLoS One. 2014;9(7):e102505.

7. Kraut A, Graff L, McLean D. Behavioral change with influenza vaccination: factors influencing increased uptake of the pandemic H1N1 versus seasonal influenza vaccine in health care personnel. Vaccine. 2011;29(46):8357-8363. 
8. Ravert RD, Fu LY, Zimet GD. Reasons for low pandemic H1N1 2009 vaccine acceptance within a college sample. Adv Prev Med. 2012;2012:242518

9. Nguyen T, Henningsen KH, Brehaut JC, Hoe E, Wilson K. Acceptance of a pandemic influenza vaccine: a systematic review of surveys of the general public. Infect Drug Resist. 2011;20 (4):197-207.

10. Ten health issues WHO will tackle this year. Available from: https:// www.who.int/news-room/spotlight/ten-threats-to-global-health-in2019. Accessed November 6, 2020.

11. de Figueiredo A, Simas C, Karafillakis E, Paterson P, Larson HJ. Mapping global trends in vaccine confidence and investigating barriers to vaccine uptake: a large-scale retrospective temporal modelling study. Lancet. 2020.

12. Lazarus JV, Ratzan SC, Palayew A, et al. A global survey of potential acceptance of a COVID-19 vaccine. Nat Med. 2020.

13. Garde D, Herper M, Branswell H, Boodman E, St. Fleur N, Joseph A. Pfizer and BioNTech Covid-19 vaccine is 95\% effective, full results show. 2020. Available from: https://www.statnews.com/2020/11/18/ pfizer-biontech-covid19-vaccine-fda-data/.Accessed November 21, 2020 .

14. Al Mulla Y COVID-19: pfizer vaccine to arrive in Kuwait in 10 days [internet]. Gulf News. Available from: https://gulfnews.com/world/ gulf/kuwait/covid-19-pfizer-vaccine-to-arrive-in-kuwait-in-10-days1.75896638. Accessed November 21, 2020.

15. Alawadhi E, Hossain A, Bin Haidar N, Zein D. Kuwait COVID-19 Snapshot MOnitoring (COSMO Kuwait): monitoring knowledge, risk perceptions, preventive behaviours, and public trust in the current coronavirus outbreak in Kuwait. PsychArchives. 2020.

16. WHO Regional Office for Europe. COVID-19 Snapshot MOnitoring (COSMO Standard): monitoring knowledge, risk perceptions, preventive behaviours, and public trust in the current coronavirus outbreak - WHO standard protocol. PsychArchives; 2020 Available from: https://www.psycharchives.org/handle/20.500.12034/2392. Accessed December 19, 2020.

17. Kuwait authorizes emergency use of Pfizer-BioNTech COVID-19 vaccine. Arab news. 2020. Available from: https://www.arabnews. com/node/1776666/middle-east. Accessed December 19, 2020.

18. Harapan H, Wagner AL, Yufika A, et al. Acceptance of a COVID-19 vaccine in southeast Asia: a cross-sectional study in Indonesia. Front Public Health. 2020;8:381.

19. COVID-19 Snapshot Monitoring (COSMO Canada) [Internet]. Impact Canada. Available from: https://impact.canada.ca/en/chal lenges/cosmo-canada. Accessed November 72020

20. Al-Mohaithef M, Padhi BK. Determinants of COVID-19 vaccine acceptance in Saudi Arabia: a web-based national survey. J Multidiscip Healthc. 2020;13:1657-1663.
21. Malik AA, McFadden SM, Elharake J, Omer SB. Determinants of COVID-19 vaccine acceptance in the US. EClinicalMedicine. 2020;26(100495):100495.

22. Pertwee E, de Graaf K, Larson HJ, Paterson P Media monitoring report: social media conversations and attitudes in the UK towards the coronavirus disease (COVID-19) outbreak.. Available from: https://static1.squarespace.com/static/5d4d746d648a4e0001186e38/t/ 5f6a31242def362d0990ad67/1600794916848/Media+monitoring +report+UK+COVID-19+10-23August2020+Final.pdf. Accessed 2020 December 20

23. Kucukkarapinar M, Karadag F, Aslan S, et al. Turkish COVID-19 snapshot monitoring (COSMO) wave-1,2,3 (17.07-31.07.2020; 01.08-15.08.2020; 16.08-31.08.2020). PsychArchives. 2020 Available from: https://www.psycharchives.org/handle/20.500. 12034/3809. Accessed December 20, 2020.

24. Monitoring of the behavior and attitudes of the population related to COVID-19 in Spain (COSMO-SPAIN): WHO Study. COSMOSPAIN. Available from: https://portalcne.isciii.es/cosmo-spain/. Accessed 2020 November 8.

25. Wang J, Jing R, Lai X, et al. Acceptance of COVID-19 Vaccination during the COVID-19 Pandemic in China. Vaccines (Basel). 2020;8 (3):482.

26. Puri N, Coomes EA, Haghbayan H, Gunaratne K. Social media and vaccine hesitancy: new updates for the era of COVID-19 and globalized infectious diseases. Hum Vaccin Immunother. 2020;16 (11):2586-2593.

27. Harris KM, Maurer J, Kellermann AL. Influenza vaccine - safe, effective, and mistrusted. $N$ Engl J Med.

28. Quinn SC, Jamison AM, An J, Hancock GR, Freimuth VS. Measuring vaccine hesitancy, confidence, trust and flu vaccine uptake: results of a national survey of White and African American adults. Vaccine. 2019;37(9):1168-1173:01033.

29. Fu C, Wei Z, Pei S, Li S, Sun X, Liu P Acceptance and preference for COVID-19 vaccination in healthcare workers (HCWs). bioRxiv. medRxiv; 2020.: doi: 10.1101/2020.04.09.20060103

30. Reiter PL, Pennell ML, Katz ML. Acceptability of a COVID-19 vaccine among adults in the United States: how many people would get vaccinated? Vaccine. 2020;38(42):6500-6507.

31. Sotgiu G, Dobler CC. Social stigma in the time of coronavirus disease 2019. Eur Respir J. 2020;56(2):2002461.

32. Baldassarre A, Giorgi G, Alessio F, Lulli LG, Arcangeli G, Mucci N. Stigma and discrimination (SAD) at the time of the SARS-CoV-2 pandemic. Int J Environ Res Public Health. 2020;17(17):6341.
Risk Management and Healthcare Policy

\section{Publish your work in this journal}

Risk Management and Healthcare Policy is an international, peerreviewed, open access journal focusing on all aspects of public health, policy, and preventative measures to promote good health and improve morbidity and mortality in the population. The journal welcomes submitted papers covering original research, basic science, clinical \& epidemiological studies, reviews and evaluations, guidelines, expert opinion and commentary, case reports and extended reports. The manuscript management system is completely online and includes a very quick and fair peer-review system, which is all easy to use. Visit http://www.dovepress.com/testimonials.php to read real quotes from published authors. 